\title{
LA COLECCIÓN DE ESCULTURAS HALLADA EN VALDETORRES DE JARAMA
}

\author{
POR \\ CARMEN PUERTA, MIGUEL ÁNGEL ELVIRA y TERESA ARTIGAS \\ Universidad Complutense de Madrid
}

\section{RESUMEN}

Las fragmentadas esculturas halladas en el edificio tardorromano de Valdetorres se pueden dividir en dos grupos: un conjunto en mármol gris oscuro, posiblemente tallado en Anatolia en la segunda mitad del siglo II d.C. y consagrado a las gestas de Apolo, y varias obras independientes, en su mayor parte representaciones de dioses, fechables en los siglos II y III d.C. Se trata de una muestra interesante de coleccionismo artistico en la época de Teodosio.

\section{SUMMARY}

The broken sculptures found in the late Roman building of Valdetorres can be divided in two parts: a group made in a dark grey marble, perhaps carved in Anatolia in the second half of the 2 nd century A.D., and devoted to Apollon's exploits, and some separated figures of gods, dated in the 2 nd or 3 rd century A.D. It's an interesting example of the artistic collecting in Theodosius' era.

La excavación del edificio tardorromano en Valdetorres de Jarama (Madrid), que fue realizada entre los años 1978 y 1982 por un equipo bajo la dirección de Luis Caballero, Javier Arce y Miguel Angel Elvira, tuvo como origen el hallazgo casual de una escultura en 1977. No han podido ser determinadas con exactitud las circunstancias de este acontecimiento, pero parece que la estatua, el Gigante de nuestras figs. 1 y 2 , apareció al acondicionarse con máquinas excavadoras el desnivel para el «camino de Madrid» que hoy bordea el edificio, en unas obras que, por lo demás, aniquilaron lo que quedase de su ábside S.O. Quedó la escultura abandonada tras los trabajos hasta que un vecino del lugar, D. Francisco Batanero, se dio cuenta de su valor y decidió entregarla al Museo Arqueológico Nacional de Madrid.

Ingresó así en dicha entidad el Gigante (com- puesto entonces por los fragmentos 77-72-la y $1 \mathrm{~b}$, más el perno de hierro que las une), $y$, fruto del inmediato reconocimiento de la zona por D. Luis Caballero, pronto se le unieron dos pedestales de la estatua y varios fragmentos escultóricos más. Era tan extraordinario el hallazgo de esta índole en la provincia de Madrid, y tan sugestivas las piezas obtenidas en la primera ojeada sobre el terreno, que se decidió acometer el programa de excavación.

No vamos a relatar aquí las distintas campañas, tarea que dejaremos para la publicación general de los trabajos. Nuestro intento es adelantar la exposición y conclusiones del conjunto escultórico (todo él en mármol) hallado en aquellas fechas, igual que hacemos, en este mismo volumen, con los hallazgos de marfil ' . Por tanto, bastará que reseñemos tan sólo los detalles que afectan directamente a nuestro cometido.

Ya desde las primeras catas que se abrieron, se advirtió un estado de suma fragmentación en los mármoles esculpidos. Aparecían además aislados, no en grupos pertenecientes a la misma estatua, y podían encontrarse en cualquier nivel. Los que se hallaban cerca de la superficie (bastante escasos, desde luego) parecian quemados, grises y sin brillo, afectados sin duda por la quema de los rastrojos. Más abajo, los restos, ya con la superficie mejor conservada, iban apareciendo en mayor número, hasta concentrarse su densidad en torno al nivel de destrucción: revueltos alli con las tejas que cubrieron el edificio, en ocasiones por encima de ellas y menos

'M. Carrasco y M. A. Elvira, "Marfiles coptos en Valdetorres». En este artículo se hallará bibliografía sobre el yacimiento. 
veces por debajo, se aglomeraban los fragmentos más distintos e inconexos. En niveles más profundos habia ya menos restos de estatuas, y muy raros fueron los hallados en el suelo primitivo del edificio.

La misma distribución irregular, pero relativamente concentrada, se pudo observar en planta, como puede comprobarse en los planos que acompañan el presente estudio. Apenas hay zonas de la casa donde no haya aparecido algún fragmento, pero los hallazgos tienden a reunirse en la zona occidental y. en concreto, en la gran habitación cuadrada que daba paso al ábside S.O. (hab. 7), en la pequeña habitación angular que se abría al norte de ésta y en la zona occidental del peristilo.

Sin embargo, dado lo fragmentario del conjunto, nos parece en exceso aventurado relacionar esta localización con el emplazamiento concreto que tuviesen las estatuas en su dia. Sólo parece haber llegado in situ, por asi decirlo, un grupo relativamente bien conservado: el que forman el Arquero 1 y el Nióbide. Sus restos aparecieron como aplastados por uno de los pilares que, rematados con arcos de ladrillo, formaban el peristilo: en concreto, el pilar del ángulo N.O. del patio. Sin duda el grupo se hallaba en su colocación primitiva cuando la ruinosa arquitectura se desplomó, arrojando fragmentos a cierta distancia y permitiendo a visitantes ocasionales trasladar y llevarse algunos restos.

Sin embargo, este caso concreto de destrucción natural no parece cuadrar con las otras esculturas. Sin una actividad depredadora es imposible explicar la pérdida de todas las cabezas humanas (salvo dos fragmentos de la del Negro) y de la mayor parte de los torsos, es decir, de las piezas más atractivas o más útiles como material de construcción. Parece, por tanto, que debieron interrelacionarse dos procesos distintos: el hundimiento paulatino del edificio, y el destrozo y saqueo consciente de las estatuas. Una vez caído el pilar que aplastó al Arquero 1 y al Nióbide, y a la vez que seguían desmoronándose techos y muros, hubo gentes que decidieron destruir el contenido decorativo del monumento. Acaso fueron las mismas que rompieron los muebles de madera y marfil, y probablemente actuaron de forma premeditada: concentraron las esculturas (incluidos algunos restos del Nióbide y del Arquero 1) en dos habitaciones, las destrozaron, se llevaron los fragmentos de mayor interés para ellos, y dejaron el resto removido entre los escombros. Aunque hipotética, esta explicación nos parece la más verosímil.

Por desgracia, carecemos de ciertos elementos que serían de suma utilidad a la hora de reconstruir la decoración escultórica del edificio: nos referimos a los podios que, en pura lógica, hubieron de sostener los pedestales de las estatuas. Si tales estructuras existieron, sus materiales fueron robados sin dejar rastro; $y$, desde luego, es imposible que las esculturas (cuyo tamaño raramente alcanza un metro de alto) estuviesen colocadas directamente sobre el suelo. Sólo caben dos alternativas: o no estaban aún instaladas en su emplazamiento previsto, o se colocaron sobre algún elemento arquitectónico, como el ancho murete que, a guisa de pasamanos, unia los pilares del peristilo; aunque un poco forzado, el grupo del Arquero 1 y el Nióbide pudo colocarse alli, adosado al pilar que lo destruyó.

\section{OBJETIVOS Y CRITERIOS DEL PRESENTE ESTUDIO}

Diseminado y roto en infinito número de fragmentos (los tres centenares llegados hasta nosotros no componen sino partes, a menudo menores, de cada estatua), el conjunto de Valdetorres presenta un problema esencial: la identificación de las distintas obras que lo componian hacia el año 400 d.C., cuando se llevó a cabo la decoración del edificio. Tal es, junto con el estudio iconográfico y estilístico de cada escultura, el objetivo básico de estas páginas.

Por fortuna, contamos con la ayuda inapreciable que nos presta la propia índole de la colección escultórica, que es su carácter heteróclito: al familiarizarse con los fragmentos, el estudioso advierte pronto que cuenta con muchos criterios para distinguir su adscripción, más o menos segura, a una estatua concreta.

Así, cabe atender, como dato de gran importancia, a la diferencia de tamaño que evidencian distintos miembros, incluso fragmentados: dada la relativa estabilidad de proporciones que presenta la estatuaria ideal romana, este dato permite fijar el tamaño de cada estatua con relativa precisión, y reunir así restos inconexos.

Por lo demás, cuenta sin duda la calidad artística del trabajo, que oscila, por poner dos ejemplos, entre la vulgar talla del Esculapio y la muy digna ejecución del Gigante. $E$ independientemente de esta calidad, interesa también el estilo, variable entre piezas más clasicistas y otras más realistas y carnosas.

Pero el criterio más visible desde el principio, y el que va a servir de trama para la ordenación de nuestro catálogo, es la diversidad de materiales marmóreos en que fueron talladas las obras. Este aspecto ha sido analizado, desde un punto de vista petrológico, por los doctores F. Mingarro y 
M. C. López de Azcona 2 y el fruto de sus investigaciones, aún a falta de resultados definitivos acerca de las canteras, permite por lo menos definir una serie de mármoles con su composición cristalográfica y química correspondiente.

En cada tipo de material pueden haber sido talladas varias esculturas. Para distinguirlas, se revela muy útil el estudio visual de las vetas o de la degradación de los tonos, cuando existen. Puede asi llegar a definirse la tonalidad concreta de cada bloque, aun teniendo en cuenta su posible transformación por incidencias casuales, como golpes, corrosiones o fuego.

Sin embargo, este método tiene un curioso límite, debido a la peculiar ejecución y posterior suerte de las esculturas hasta su instalación en Valdetorres. En efecto, es muy común la presencia, en casi todas las estatuas, de superficies de contacto alisadas y preparadas con golpes de puntero para pegar entre si distintos fragmentos; e incluso se aprecian a menudo agujeros para pernos que aseguren la unión. Pues bien, puede ocurrir que dos miembros destinados a ser unidos sean del mismo bloque, y con las vetas coincidentes, en cuyo caso habremos de pensar en la reparación de una rotura; pero también es posible advertir una marcada diferencia en vetas y color, en cuyo caso caben, creemos, dos explicaciones alternativas: si el trabajo y estilo resultan coincidentes a ambos lados del corte, lo interpretaremos más bien como un recurso de fábrica ante la escasez de bloques de suficiente tamaño, o ante una rotura fortuita en el proceso de la talla; si, por el contrario, es manifiesta la diferencia de estilo o calidad, resulta más lógico suponer una restauración apresurada.

En Valdetorres se dan todos los supuestos, e incluso otro muy curioso: el de la peculiar relación que hay entre las esculturas y los pedestales. Como tendremos ocasión de ver en múltiples figuras, los pies no formaban bloque con el pedestal correspondiente, sino que, aun conservando a menudo restos de una base bajo las plantas, se asentaban, fijados con pernos metálicos, sobre pedestales de un mármol blanco de grano grueso. Evidentemente, siempre se puede pensar en una técnica de fabricación destinada a ahorrar los materiales más caros o a dar colorido a las estatuas, pero podemos adelantar que la tosquedad de la talla de los pedestales sugiere otra posible alternativa: la intervenciones a posteriori, encaminadas a unificar el aspecto de todas las obras.

${ }^{2}$ F. Mingarro Martín et alii, «Petrologia arqueológica de esculturas procedentes de la villa romana de Valdetorres de Jarama (Madrid)", Rev. Mat. Proc. Geol., V, 1987 p. 45-70.
Sin embargo, éste y otros detalles técnicos, como la unión decorativa de distintos materiales, pueden $y$ deben ser vistos analizando las piezas una por una.

\section{ESCULTURAS EN MÁRMOL GRIS OSCURO VETEADO}

Si hacemos abstracción de un único fragmento rojo, que mencionaremos al final, las esculturas de Valdetorres son de color blanco o de color oscuro. $\mathrm{Y}$ de estas últimas, todas salvo una están realizadas en el material que corresponde al presente apartado, y que aparece definido en el estudio de F. Mingarro y M. C. López de Azcona bajo el nombre de «muestra $\left.n^{\circ} 8\right)^{3}$. Se trata de un mármol gris azulado oscuro, negruzco en ocasiones y con vetas suaves más claras y poco marcadas. De entre los mármoles conocidos por la bibliografía, el más parecido sería el bigio antico en sus variantes más oscuras .

Dado la rareza de este mármol (prácticamente desconocido en la estatuaria romana de nuestra peninsula), puede darse casi por seguro el origen común de todas las estatuas de Valdetorres talladas en él, que constituyen la mitad de la colección completa. Por la misma opinión aboga el hecho de que, con la única salvedad del Desconocido $\mathrm{A}$, todas las figuraciones alcanzasen unos $90 \mathrm{~cm}$. de alto, y que la calidad y estética de su talla resulten bastante homogéneas.

Por lo demás, y aun dejando para las conclusiones de este apartado diversas sugerencias sobre el carácter y origen del conjunto, cabe repetir que el Nióbide y el Arquero 1 formaban un grupo, aunque los estudiemos por separado, y anunciar que otro tanto ocurrió sin duda con el Gigante y el Arquero 2 (lo que nos permite adelantar de paso, la identificación de ambos arqueros con el flechador Apolo). A su debido tiempo volveremos sobre estas iconografias, explicándolas y justificándolas con más detalles, pero hay que tenerlas en cuenta desde el principio para entender, por ejemplo, el desequilibrio del Gigante y el Nióbide tomados como figuras independientes.

\footnotetext{
${ }^{3}$ Véase artículo citado en la nota anterior, p.49, B (donde hay errata, pues debería decir «Fig. 3 y $4 »)$, y p. 62 , con fig. 11 .

4 Sobre este mármol, cuyas canteras se extienden por diversas zonas de Anatolia occidental y en las islas inmediatas de Egeo, véase E. Dolci y L. Nista, Marmi antichi da collezione, Carrara, 1992, foto 94 y p. 69; R. Gnoli, Marmora romana, Roma, 1971 , p. $152-153$ y fig. 201; H. Mielsch, Buntmarmore aus Rom im Antikenmuseum Berlin, Berlin, 1985, lám. 18, nº 629 y 633: M. L. Anderson y L. Nista (ed.), Radiance in Stone. Roma, 1989. p. 64 .
} 


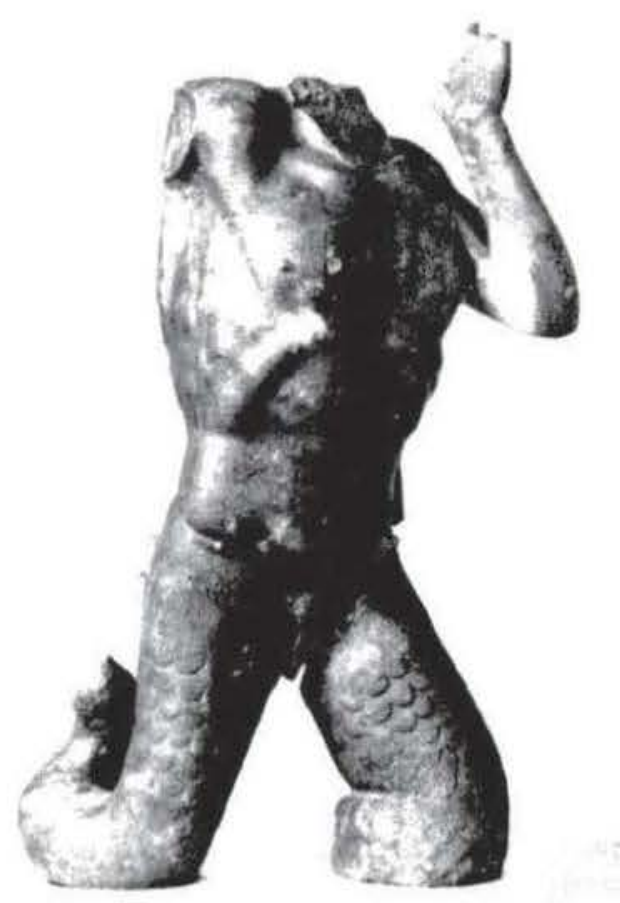

Figura 1. Gigante de frente, restaurado.

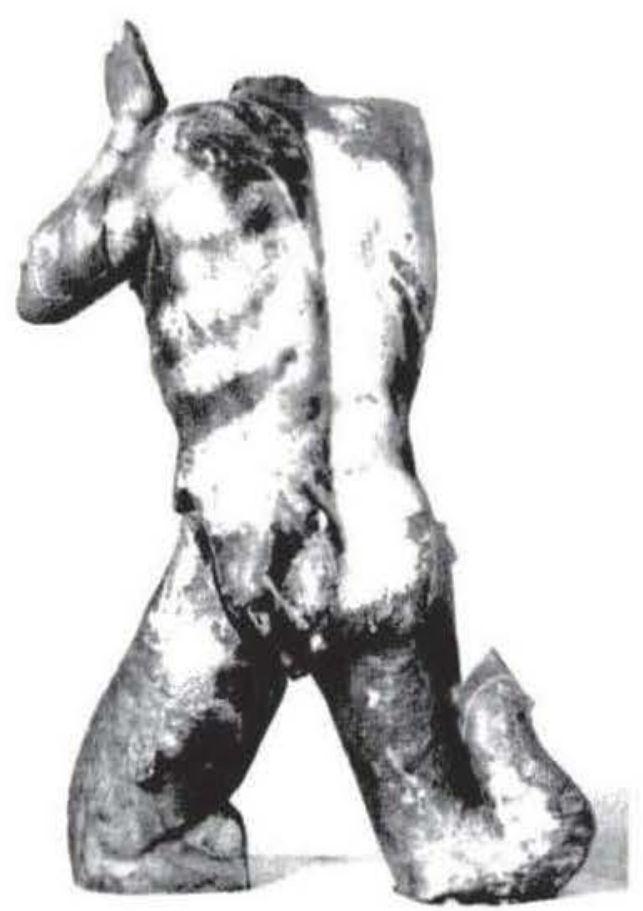

Figura 2.-Citgante de espaldas, restaurado.

\section{Gigante (figs. 1 y 2)}

Fragmentos que lo componen: 77-72-1a y $1 \mathrm{~b}, \mathrm{II}$ 172 a y b (todas estas piezas pegan entre si).

Altura de la estatua conservada: $61 \mathrm{~cm}$. Altura probable de la estatua completa: $87 \mathrm{~cm}$.

Estado de conservación: Faltan brazo y mano derecha, cabeza con casi todo el cuello. dedos de la mano izquierda. organo sexual y remate de las piernas serpentiformes. Ilay desperfectos superficiales, y en particular surcos blanquecinos causados por algún objeto metálico.

Detalles técnicos: Se aprecian toques de puntero en la superficic inferior de las patas, y toques de cincel $y$ de trèpano entre ellas y en los genitales. La pata izquierda, tras una rotura, fue reintegrada al conjunto mediante un perno de hierro (long.: $16 \mathrm{~cm}$.: diám.: $1.1 \mathrm{~cm}$.) alojado en sus agujeros correspondientes, que se ha conservado. Por el mismo sistema se unian al pedestal las dos patas.

- Notas descriptivas ${ }^{5}$ : Gigante anguipedo que se lanza hacia adelante, en diagonal, apoyándose en su pata izquierda. Ambas patas, decoradas con escamas, se doblan violentamente hacia atrás, $y$ puede afirmarse, por los restos de un puntero, que la parte final de la pata derecha, tras tocar la parte trasera del muslo correspondiente, se separaba del cuerpo hacia atrás y hacia la derecha. EI bien

En aras de la brevedad, limitamos nuestras descripciones a detalles poco visibles, o que permiten reconstruir partes perdidas de la obra, o que mencionan algún elemento útil para el estudio.

modelado torso concluia en una cabeza que, por los restos conservados del cuello, no debia inclinarse ni girar mucho en ningùn sentido. La mano izquierda parece protegerla. mientras que el antebrazo derecho, hoy perdido. debia dirigirse en dirección casi horizontal y algo hacia atrás.

Puesto que la iconografia del Gigante anguipedo, nacida en ambiente suditálico a fines del siglo Iv a.C., no se generaliza hasta el Alto Helenismo, a raiz de la realización de la famosa Gigantomaquia de Pérgamo, es a partir de ese momento cuando debe situarse la creación del tipo representado en nuestra escultura ${ }^{\circ}$.

Lo primero que cabe resaltar es la suma rareza de gigantomaquias en bulto redondo conservadas en escultura helenistica y romana: si excluimos el exvoto de Atalo en la Acrópolis de Atenas (LIMC, 23), cuyos gigantes no son anguipedos, la única gigantomaquia que podemos mencionar es la del conjunto de Silahtaraga, de la segunda mitad del siglo ॥ a.C., hallada cerca de Estambul y conservada

\footnotetext{
- Para la iconografia del Gigante, véanse sobre todo F. Vian, Répertoire des gigantomachies figurées dans l'art grec et romain. Paris, 1951, y Lexicon Iconographicum Mythologiae Classicae (LIMC). Zurich/Munich, v.a.. IV.,s.v. "Gigantes", por F. Vian y M. B. Moore. Para citar las piezas, usaremos la numeración de esta última obra.
} 
en su museo ( $L I M C$. 488 ): sus Gigantes, tallados en piedra negra y con tamaño parecido al del nuestro. constituyen posiblemente el paralelo más cercano que se puede aducir, y no deja de ser coincidente el hecho de que apareciesen sobre bases blancas, y acompañados por dioses blancos?. Las semejanzas entre Silahtaraga y Valdetorres son tantas que ya habremos de volver a ellas en las conclusiones, pero, anunciémoslo ya, ello no implica una absoluta identidad en su iconografia e historia.

Cabe tener en cuenta, por ejemplo, que en Valdetorres no hay una verdadera gigantomaquia, sino un simple combate individual extraido de ella. Por tanto, podemos buscar nuevos paralelos en las escasas esculturas exentas que presentan esta iconografia: si excluimos obras de carácter excesivamente local, como los combates de "Júpiter» y el anguipedo ( $L I M C, 533$ ) o del "Jinete» y el anguipedo ( $L I M C$. 534), aún nos queda un grupo aislado de carácter clasicista comparable al nuestro: el conservado en Wilton House con la lucha entre Heracles y un Gigante $(L I M C, 27)$; por desgracia, poco sabemos de su origen y de su presunta cronologia de época helenistica.

Nuestro Gigante se enfrenta, como ya hemos anunciado, a Apolo; y esta escena, separada del resto de la gigantomaquia, es muy rara también, tanto en escultura como en pintura: sólo conocemos un paralelo aducible - el de los relieves del teatro de Hierápololis (Pamukkale) (LIMC, 483), de principio del siglo III d.C., sobre los que habremos que retornar $^{8}$ - , aunque hay importantes diferencias de detalle.

No cabe por tanto extrañarse de la falta de paralelos exactos para la forma y postura del Gigante de Valdetorres. Y, sin embargo, no podemos excluir un posible prototipo muy antiguo, si aceptamos la semejanza de uno de los Gigantes que se enfrentan a Apolo en el friso con gigantomaquia del Hecateion de Lagina (LIMC, 28; fines del siglo II a.C.), aunque la figura nos haya llegado muy incomple$\mathrm{ta}^{9}$. Ya en época imperial, el mejor paralelo es el Gigante que huye de Atenea en el friso de una fuente de Afrodisias (LIMC, 485), de mediados del siglo II d.C.; sin embargo hay una curiosa diferencia: este último Gigante levanta en su mano izquierda una piel de animal, mientras que la figura de Valdetorres se lleva a la cara la palma de la mano, como si

7 N. de Chaisemartin y E. Örgen, "Les sculptures de Silahtaragan, $R A, 1983$, fásc. 1 , p. 181-189.

' F. d'Andria y T. Ritti, Hierapolis II. Le sculture del teatro: I rilievi con i cicli di Apollo e Artemide, Roma, 1985, p. 12-13.

- A. Schober, Der Fries des Hekateions von Lagina (Ist. Forsch., 2), 1933, lám. XXIl. ilustrase el texto de Apolodoro (Bibl., I (34-38) 6, 2): «Apolo alcanzó con una flecha a Efialtes en el ojo izquierdo" (citado en LIMC. p.191).

Estilisticamente cabe señalar que el Gigante de Valdetorres resulta más esbelto y clasicista, con la estructura del cuerpo mejor marcada, que la práctica totalidad de los relieves y esculturas realizados en Asia Menor, y se acerca bastante, en cambio, a un sarcófago con gigantomaquia tallado en Roma en la 2." mitad del siglo $\|$ d.C., y hoy en el Vaticano (LIMC. 502). Sin embargo, no se trata de un dato definitivo: hallamos el mismo sentido clasicista en un Gigante en alto relieve que, enfrentado a Atenea, integraba en el santuario de Atenea Priene un monumento de época imperial ${ }^{10}$.

\section{Nióbide (figs. 3 y 4 )}

Fragmentos que lo componen: Conjunto formado por II-A, B y B.1, SALA-1, 3, 4 y 5, I-M-111, II-15I, II155. II-156; conj. form. por III-884, III-886; conj. form. por IV-1312, III-883; conj. form. por IV-62I, II-86; II153; conj. form. por IV-586, I-M-100; IV-602; I-M-14; I-M-95: IV-589: V-2152: II-154; II-278: I-M-54 y IV797.

- Altura de la estatua conservada: $61 \mathrm{~cm}$. Altura probable de la estatua completa: $88 \mathrm{~cm}$.

-Estado de conservación: Aunque está muy destrozada, se pueden reunir los distintos fragmentos y reconstruir un conjunto congruente y seguro en lineas generales. El Nióbide carece de toda la cabeza hasta la parte baja del cuello, y también ha perdido importantes partes de ambos brazos y sendos fragmentos en el empeine del pie derecho y en la zona posterior de la cadera izquierda; además, aparecen erosionados superficialmente su pie izquierdo y un sector de la espalda. Al caballo le falta toda la parte posterior del cuerpo desde la grupa, con la excepción de las patas y pezuñas traseras y de un sector de la cola. En la parte anterior, le faltan también la mitad derecha del pecho y del cuello, casi toda la pata derecha (salvo la pezuña y un fragmento inmediato) y la mitad izquierda de la grupa, acaso rota longitudinalmente. La cabeza ha perdido el morro y presenta erosionada la superficie. Algunos fragmentos aparecen blanqueados por el fuego.

-Detalles técnicos: Bajo la estatua, y en su mismo bloque, se talló una base que aparece como una simple lámina en alguna zona (por ejemplo, bajo la pata delantera derecha del caballo). Diferencias de material seña-

10 J. C. Carter, The Sculpture of the Sanctuary of Athena Polias at Priene, Londres, 1983, p. 177-180, lám. XXIV, abajo. Algo más blando, pero no muy diverso, es el tratamiento de los gigantes (alguno de ellos anguipedo) en la gigantomaquia en relieve del teatro de Corinto, fechada en el segundo cuarto del siglo II d.C. (LIMC, 481: M. G. Sturgeon, Corinth. IX, II. Sculpture: The Reliefs from the Theater, Princeton, 1977, passim $\mathrm{y}$, sobre todo lám. 13 y 29). 


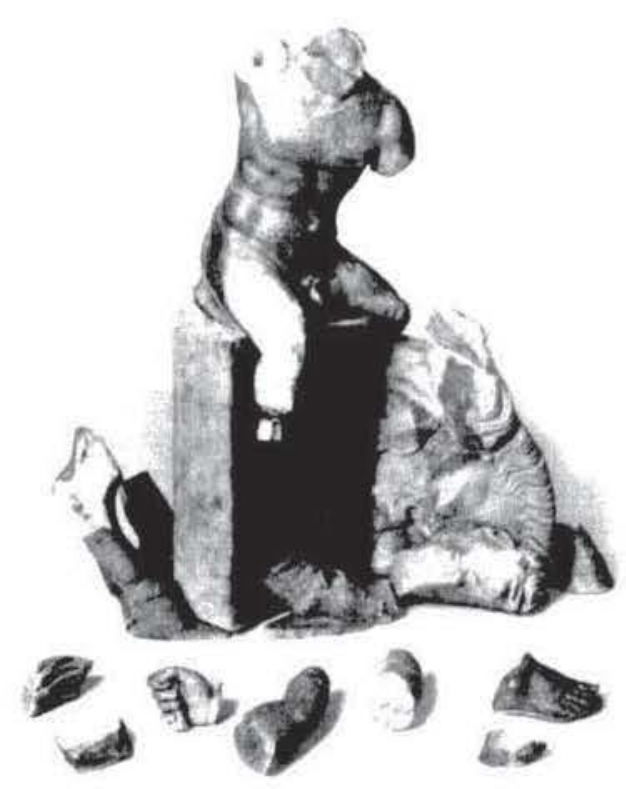

Figura 3.- Niobide de frente, restaurado.

lan que la pata trasera izquierda del caballo fue trabajada aparte. Distintos taladros muestran la unión artificial de la pierna y el pie derecho del Nióbide, del hombro y el brazo derecho de la misma figura (en este último caso, una restauración), de la estatua en su conjunto y el pedestal, y de la espalda del Niobide y un panel de fondo (en esta ocasion, con una capa de cal como refuerzo). Se aprecian huellas de puntero en las zonas invisibles, como la parte inferior de la base y un sector del pecho del Nióbide, destinado a recibir como aplique una clámide de otro material. En diversos puntos aparecen huellas de cincel $y$ de trépano, Los ojos del caballo están tallados en hueco, para recibir otro material como relleno. En general. se manifiesta gran descuido en la parte posterior de la estatua, que es la del lado izquierdo del caballo.

- Notas descriptivas: La escultura representa un caballo cayendo de frente y arrastrando en la diagonal de su caida a su joven jinete. En la montura resultan de particular interés las orejas, esculpidas como tallos vegetales, y las crines, realizadas como una sucesión de mechones en $\mathrm{S}$ prácticamente idénticos. El jinete muestra en su pie derecho una sandalia o caliga, tipico calzado de jóvenes o cazadores, mientras que el pie izquierdo. por quedar oculto a la vista del espectador, apenas está esbozado. El brazo izquierdo se alarga quizá en exceso para agarrarse a las crines del caballo; en cambio, el derecho se lanzaba hacia arriba y hacia atrás, resaltando la diagonal del conjunto. Minimos restos nos señalan que el joven tenía una corta melena que cubria el cuello por detrás. Como hemos señalado, hubo de llevar sobre el pecho una clámide de otro material (quizá del mármol rojo que citaremos más adelante). La mano derecha (fragmento (V-797), casi con seguridad perteneciente a esta

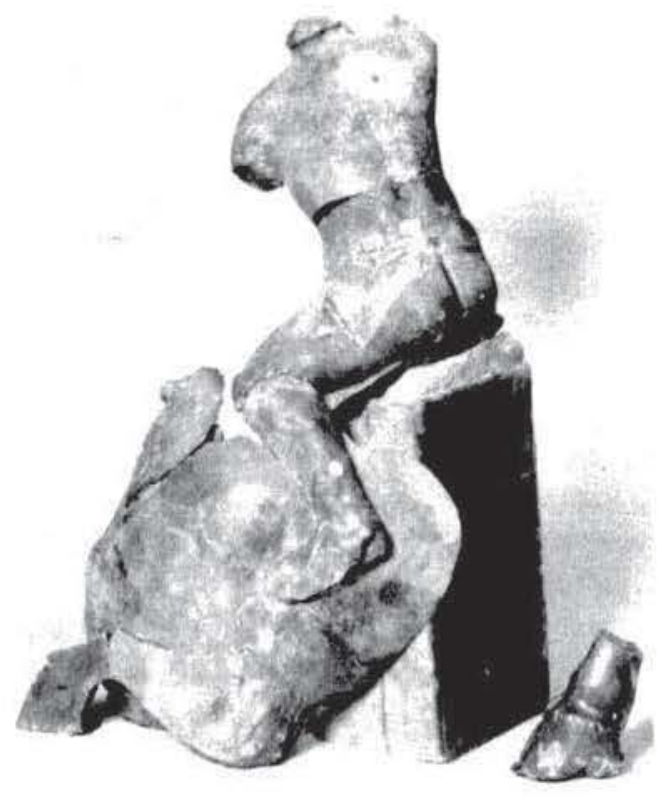

Figura 4.-Niobide de espaldas, restaurado.

figura, empuna un objeto cilindrico que concluye junto al dedo meñique, pero que continuaba más allá de los dedos indice y pulgar.

Pese a la falta de atributos concretos, esta obra debe identificarse, $y$ asi venimos haciéndolo, como un Nióbide a caballo en el momento de ser abatido por las flechas de Apolo: en efecto. la naturaleza de su oponente, el Arquero 1, cuyos fragmentos aparecieron en buena parte junto a ál, no permite otra alternativa verosimil +1 .

La iconografia de los Nióbides a caballo ${ }^{12}$, basada en la idea de que fueron muertos durante una cacería ${ }^{13}$, no es muy común: si dejamos aparte una escultura etrusca en terracota, de interpretación discutida y con formas diferentes del tipo que nos interesa ${ }^{14}$, y si nos limitamos a mencionar de paso

II Han de excluirse otras iconografias formalmente proximas, como la de Troilo (S. Reinach, Répertoire des reliefs grees et romains. Paris, 1912, II, p. 191, fig. 2) o la de un barbaro (ibidem, III, p. 433, fig. 1), pues en ellas el enemigo llevaria espada, no arco.

2 De nuevo utilizamos como libro de referencia el $\angle I M C$, en este caso vol, VI, s.v. «Niobidai», por G. Geominy.

is Ovidio, Met., VI, 170ss., véase LIMC, p, 928.

14 LIMC, 53 (en el capitulo de las iconografias inseguras): $\mathrm{R}$. M. Cook, Niobe and her Children. Cambridge, 1964, p. 49, n 21. (Florencia, Mus. Arch. Etr.); J, Martha, L arı étrusque. 1889. 326; A. Andrén, Architectural Terracottas from Etrusco-Italic Temples, Lund/Leipzig, 1939, lám. 96. Se trata de una obra del siglo ॥ a.C. 
una pintura pompeyana ${ }^{15}$. ya mucho más próxima al esquema de nuestra estatua (pero con el Nióbide vestido), sólo podemos aducir, en relieve, los cuatro sarcófagos de taller romano, fechables entre 140 y 200 D.C., que componen el "Segundo Grupo" del catalogo de Robert ${ }^{\text {in }}$.

$Y$, en efecto, en tres de estas obras (la cuarta, la conservada en Providence, ha perdido el sector que aqui nos interesa) hallamos, a la derecha de la composición, dos Nióbides, uno en el primer plano y otro detrás de él, que of recen notables semejanzas, incluso de estilo y de tratamiento epidérmico. con la escultura de Valdetorres.

Sin embargo, resulta imposible hablar de un paralelo exacto. El Nióbide del primer plano en los sarcófagos del Vaticano y de Venecia (LIMC, 32 a y b) monta un caballo que, a primera vista, parece la inversión especular del nuestro, pero que está completamente tumbado. En este punto nuestro caballo se parece más al del segundo plano en el sarcófago de Wilton House ( $L I M C, 32$ d).

Por lo que se refiere al jinete, la situación es semejante: la inclinación general del de Valdetorres recuerda a los Nióbides del primer plano de los sarcófagos: en cambio, la postura del brazo derecho alzado, con un objeto cilindrico entre los dedos, evoca más bien el gesto de arrancarse una flecha que hacen los Nióbides del segundo plano. En los detalles menores, las divergencias se multiplican: en los sarcófagos, los jóvenes van descalzos y usan riendas, en abierta contradicción con nuestra figura, $y$ ihasta qué punto podemos asegurar que el grueso cilindro que empuña esta última representa una flecha? Aceptamos que, pese a las concomitancias, no se puede hablar de una relación directa e inmediata entre el Nióbide de Valdetorres y los sarcófagos romanos, aunque si, quizá, de un modelo común.

\section{Arquero 1 (fig. 5)}

-Fragmentos que to componen: Conjunto formado por III-888, II-125, V-1118, III-890, III-889, IV-1582, III-885; conj. form. por III-887, IV-585 a y b, IV-596; conj. form. por I-M-19, I-M-94, I-M-98, IV-804, I-M107; conj. form. por III-912. III-880; y cuatro frag. que también podrian ser del arquero 2: 1-M-90, I-M-96, V1984 y V-1181.

Is LIMC. 14. Pompeya, Casa Reg. VII, ins. 15, 2: véase por ejemplo en EAA, s. v. "Niobe e Niobidi", fig. 672. Es de fines del siglo i a.C.

t6 C. Robert, Die antiken Sarkophag-Reliefs. III, 3, Berlin 1919. p. 373 ss. (donde se añaden unos fragmentos inconexos que no afectan a las figuras que nos interesan aqui). Véase $L I M C, 32$ ad, y, además, R. M. Cook, op.cit. en nota 14, passim; E. Löwy. "Niobe». Id.I. 42, 1927, p. 80 ss, y M. O. Renger, "The Providence Niobod Sarcophagus", A.J.A. 73, 1969, p. 179ss.

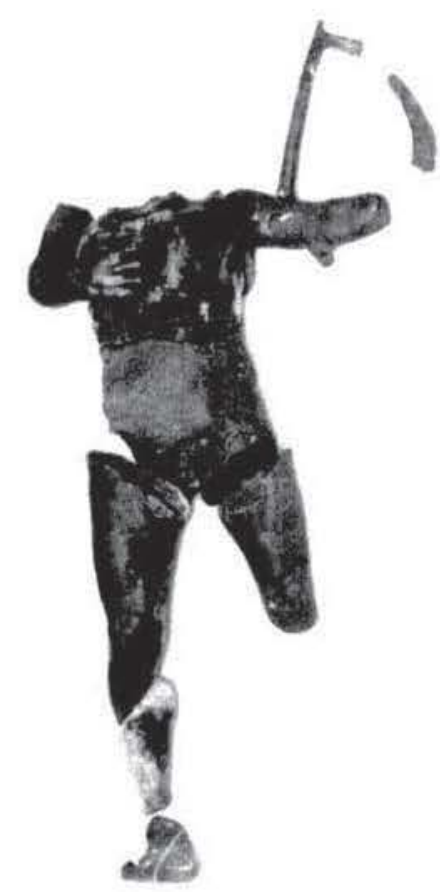

Figura 5. Arquero I

Altura de la estatua conservada: $75 \mathrm{~cm}$. Altura probable de la figura completa: $90 \mathrm{~cm}$.

Estado de conservación: A su estado fragmentario añade el problema de la dudosa adscripción de algunas piezas, como el empeine derecho y algunos restos de puntales de sujeción. De cualquier modo, la construcción general de la estatua es segura, y faltan la punta del pie derecho, toda la pierna izquierda desde la rodilla, el pecho y el vientre desde el cuello hasta la ingle, la cabeza y el cuello, el hombro derecho, el dedo meñique de la mano derecha, la mano izquierda, la mitad superior del puntal que representa la cuerda del arco, y buena parte del propio arco. Se aprecian muchas erosiones, sobre todo en la espalda.

-Detalles técnicos: Hay muy pocas huellas de talla, salvo la del trépano que traza un surco entre el pie y la base. Se ven golpes de puntero bajo la base (reducida a una fina placa) y en la superficie plana donde el empeine debia recibir, como aplique, los dedos del pie. Los dedos de la mano derecha están unidos por pequeños puntales. Existe una huella de perno en el brazo izquierdo, y un perno de hierro destinado a fijar un dedo de la mano derecha. Por lo demás, el arco muestra signos evidentes de haber sido restaurado mediante el alisamiento de un sector y el añadido de una grapa de hierro (que aún se conserva).

- Notas descriptivas: Representación de un arquero desnudo en pie, que tensa el arco hacia su izquierda, dentro de un esquema bidimensional. Las dos piernas sostienen por igual el cuerpo, y se marcan fuertemente sus músculos, igual que los de la espalda. El único elemento que acaso rompiese, minimamente, el carácter frontal de la figura sería el brazo derecho, si es que pasó, como parece 
mas logico. por delante del pecho. En el areo se definen bien la agarradera central. cilindrica, y las dos mitades. que se exvasan junto a la agarradera para irse estrechando hacia los extremos: estos se recurvan fuertemente hacia adelante, y de ellos parten. para unirse con el antebrazo i/quierdo, unos puntales de sección cuadrangular que quieren representar la cuerda recién soltada de la mano derecha entreabierta.

No puede entenderse esta escultura sin tener en cuenta que apareció junto al Nióbide, y que formó grupo con èl. Estéticamente, es incluso necesaria esta vinculación, que explica la bidimensionalidad de ambas piezas y que permite crear una composicion equilibrada colocando el arquero a la izquierda y el Nióbide de la derecha.

Si esta interrelación nos ha ayudado a fijar la iconografía del Nióbide, también determina la identificación del arquero como Apolo; y ello a pesar de algunas anomalias, como la absoluta desnuder de su cuerpo ( no sólo carece de clámide, sino tambièn de carcaj y de sandalias) o su musculatura muy desarrollada: en efecto, no son éstos obstáculos insalvables, pues conocemos Apolos tan musculados como el Diadúmeno de Policleto ( que sin duda representó a este dios), y no faltan ejemplos desprovistos de todo atributo o vestimenta ${ }^{17}$.

Resulta también peculiar en nuestro Apolo la actitud general del cuerpo, pues lo más normal es que este se lance hacia adelante o camine de puntiIlas (LIMC. 75) y que, para tensar la cuerda, avance la mano derecha hasta la altura del brazo izquierdo (LIMC, 70, 1075, 1079, etc.), o la baje sobre el vientre (LIMC, 76, $1001 \mathrm{c}$, etc.), o la coloque tras la cabeza (LIMC, 324, 1066, 1077, etc.). Sin embargo, ni es imposible que nuestro arquero tuviese su mano en esta última postura (aun siendo más lógica su colocación sobre el pecho), ni, por lo que se refiere al cuerpo en general, faltan relieves que se aproximen mucho a la postura de nuestra estatua: tal es el caso, en lo que podemos colegir, de los Apolos que aparecen en las gigantomaquias del Altar de Pérgamo y del Hecateion de Lagina (LIMC, 1061 y 1064) $y$, ya en época romana imperial, de los que vemos una moneda de cobre de Tralles, fechada en la época de Cómmodo (LIMC, 79 a), y, pocos años después, en el relieve de la lucha contra un Gigante que ya hemos visto en Hierápolis ${ }^{18}$. Concluyamos que

17 Para la iconografia de Apolo tomamos, de nuevo, como libro de referencia el $L I M C$. en este caso vol II, s. v. "A pollon", por W. Lambrinudakis et alii. Entre los Apolos desnudos cabe citar el del tipo Lykeios de Dresde ( LIMC, $39 \mathrm{n}$ ), o alguna moneda con el mismo tipo (LIMC, 39 e), por no aludir a ejemplos más arcaicos.

${ }^{18} \mathrm{~F}$. d'Andria y T. Ritti op.cit. en nota 8 , lám. 13, 3.

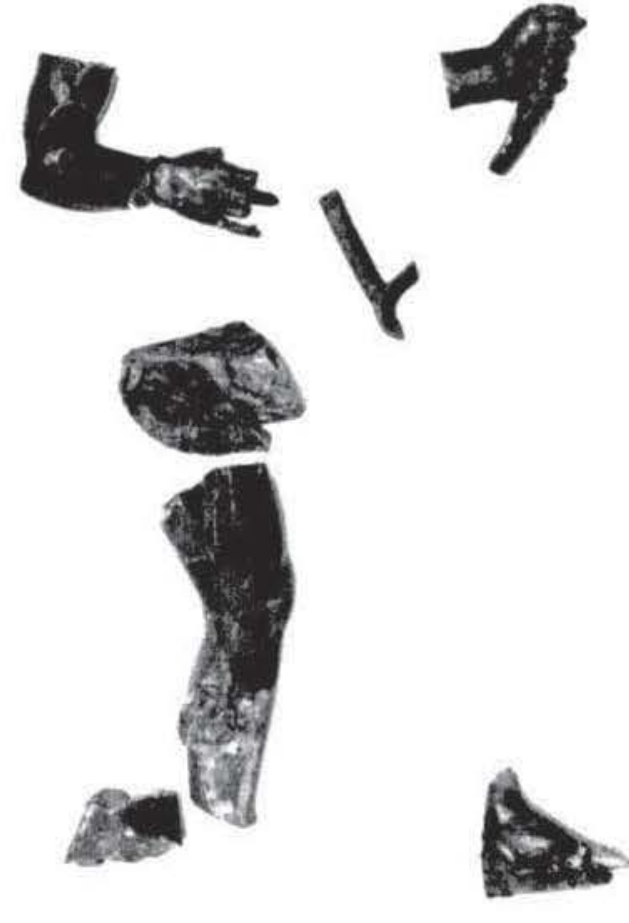

Figura 6. Arquero 2

nuestro tipo de Apolo no es único como tal, aunque si en su emparejamiento con un Nióbide.

Por lo demás, los detalles estilisticos del Arquero, con su musculatura carnosa y muy marcada, le aproximan mucho al Nióbide y a los trabajos más comunes del Asia Menor Imperial, sobre todo durante el siglo $\|$ d.C. En cuanto al tipo del arco, es muy vulgar en escultura, y el detalle de la figuración plástica de la cuerda se da también en otras obras de ese mismo siglo ${ }^{19}$.

\section{Arquero 2 (fig. 6 )}

- Fragmentos que lo componen: Conjunto formado por III-690, 77-72-5; conj. form. por I-M-43, I-M-93, V390; conj. form. por 11-190, V-1016, IV-622; conj. form. por I-M-15, 1-M-27; conj. form. por IV-600, II-88; conj. form. por I-M-13, I-M-34; conj. form. por IV-6I4, IV615 , IV $-619 ; \mathrm{V}-47 \mathrm{I}$ a y b; seis frag. que probablemente pertenecen a esta obra, aunque podría atribuirse al Arquero 1: V-389 a y b, 1-M-33, 1-M-11, 1II-22, I-M-12; y los cuatro fragmentos que pueden ser de cualquiera de los dos arqueros: 1-M-90, 1-M-96, V-1984, V-1181.

19 Puede verse este detalle en las tapas de los ya citados sarcófagos del Vaticano y en Providence, y tambièn de un sarcófago de Nióbides de otro tipo conservado en Munich (E. Löwy, op cit. en nota 16 , fig. $1 ;$ LIMC, s.v. «Apollon/Apolo», 479 a). 
Altura de la estatua conservada (en reconstruccion idcalf: $75 \mathrm{~cm}$. Altura probable de la figura completa 9) $\mathrm{cm}$

Estado de conservacion: Fista sbra está reducida a fragmentos inalga. pierna derecha, brazo y mano derecha. frag de arco. restos de un tronco-puntual. cte.). pero cuanto de ella se conserva tiene un paralelo exacto en Arquero. I. lo que permite una reconstruccion ideal idéntica a la de este

Detalles tecnicos: Los dedos de la mano derecha aparecen undos por puntales. y hay varias hucllas de pernos. Se aprecia trabajo de trépano entre los dedos de la mano y entre el pie y la base. y esta úlima. por la parte inferior, muestra golpes de puntero

Notas descriptivas: (uanto pucde observarse parece identico al Arquero 1: solo podria hablarse del tamano levemente mayor de algun detalle (por ejemplo, las manos). y de la mayor seguridad de que el Arquero 2 se apoyase en un puntal de forma de tronco de arbol.

La presente figura, reducida a fragmentos inconexos, parece idéntica al Arquero I, lo que invita a identificarla también como Apolo y a buscarle un contexto parecido: por tanto. lo más lógico es pensar que formase grupo con el Gigante, el cual, tanto por su propio desequilibrio como por razones iconográficas, necesita un oponente vencedor. Ahora bien, pueden plantearse hasta tres soluciones para colocar las dos figuras en un grupo bidimensional: 1) Apolo a la izquierda, de frente al espectador $y$ asaeteando por detrás al Gigante; 2) A polo en el mismo lugar y postura, pero enfrentándose cara a cara al Gigante, que daria la espalda al espectador: 3) Apolo a la derecha y de espaldas, atacando de frente al Gigante. $Y$ lo cierto es que no sabemos decidirnos por ninguna de las tres posibilidades. puesto que en el Gigante no hay, como en el Nióbide. una parte anterior y otra posterior netamente marcadas por la diferencia de talta. Las dos primeras soluciones pueden apoyarse en ejemplos conocides. como los frisos de Lagina y Hierapolis. respectivamente: en cuanto a la tercera, resultaria sin duda novedosa y osada, pero tendria la virtud de crear un grupo simetrico al de Apolo y el Nióbide. y no paralelo a él. con lo que esto supone a la hora de imaginar una composicion que reuniese todas las figuras comentadas hasta ahora.

\section{Sätiro con odre (fig. 7)}

Fragmentos que to componen: Conjunte formado por 1-M-44, I-M-99, IV-800: conj- form por 1-M-97, IV588, V-391: conj, form por I-M-25, 1-M-3:1-M-5; y conj. form, por II-317. III-576, III-577, III-578, III-579. III$580,111-581.111-582,111-583$

Longitud probable de la figura completa: Unos 100
$\mathrm{~cm}$. Estado de conservación: Muy fragmentario; quedan restos de la pierna derecha, dos dedos del pie izquierdo sobre una base ondulada, el brazo izquierdo con un odre. dedos de la mano izquierda con el borde de un conducto de salida de agua, y el borde de otro conducto semejante.

Detalles técnicos: Se aprecian golpes de puntero bajo la base y algun toque de cincel aislado. En el interior de los conductos de agua hay huellas sesgadas de trépano. El odre está taladrado para el paso del agua; en cambio, no se ven agujeros de pernos.

Notas descriptivas: Puede reconstruise idealmente, con muchas lagunas, la figura de un musculoso Sátiro reclinado sobre una superficie rocosa, con la cabeza hacia la derecha del espectador. y apoyando su hombro y brazo izquierdo sobre un odre. Su pierna izquierda esta-

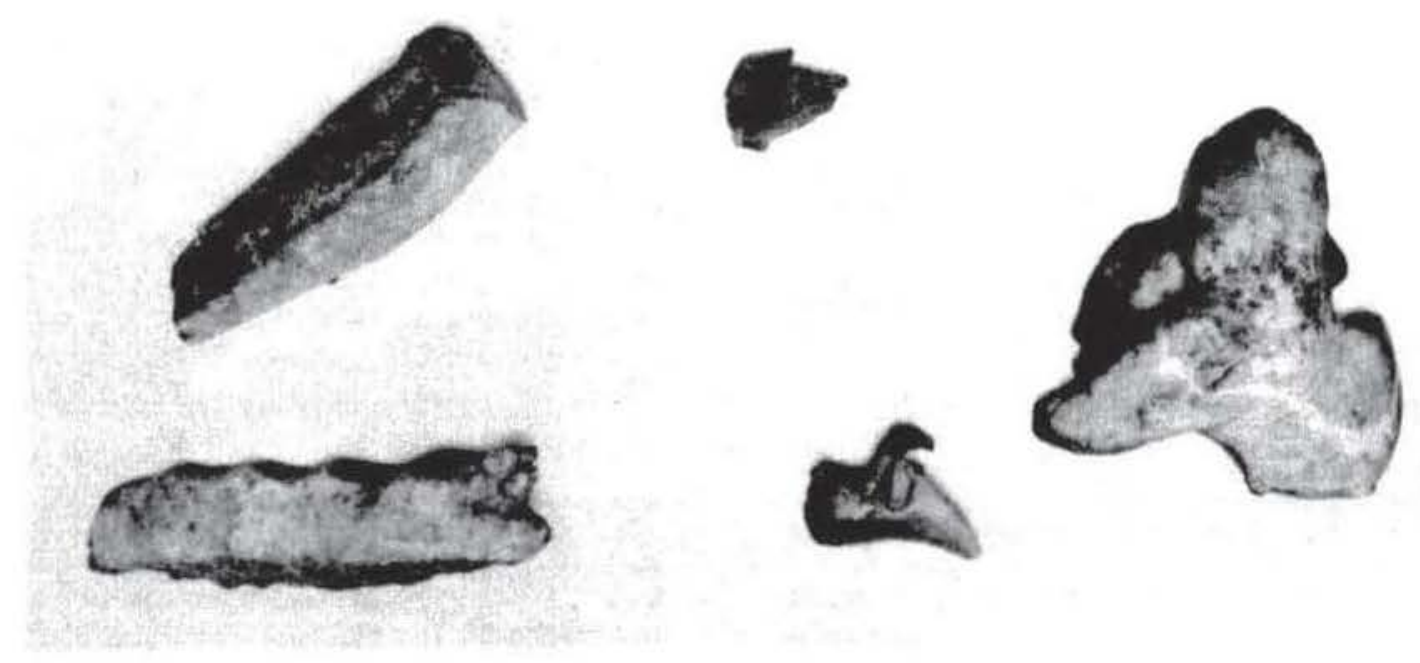

Figura 7.-Sátiro con odre. 
Hat fuentemente plegada, segun se deduce de la coloseacoon de los dedos del pee, mientras que la derecha pareceria estirada. Esta escultura fue construida para servir como fuente. lo que explica su taladro interno y las dos salidas de agua conservadas. Ahora bien, resulta problemática la interpretacion de estas tiltimas st una ha de ser la embocadura del odre. la otra acaso sea el borde de un rhwerm, o la embocadura de otro odre caso iconograficamente excepcional). o incluso un testmonio aistado de otra hipotetica fuente escultorica.

Nos hallamos ante una de las numerosas fuentes en forma de Sátiro que nos ha legado la escultura romana, estudiadas en detalle por B. Kapossy ${ }^{20}$. De su libro se deduce que no existió ningún prototipo fijo, sino que cada escultor mantenia un cierto grado de creatividad. Por tanto, bastará que señalemos, entre las esculturas más parecidas a la nuestra, los dos Paposilenos del teatro de Arlés ${ }^{21}$, un Sátiro joven en el Vaticano ${ }^{22}$, el Sátiro, hoy perdido, de Vienne ${ }^{23}$ y, ya en nuestra peninsula, el Sátiro durmiente hallado en Zaragoza 24 .

También hay estatuas de Sátiros parecidas, pero que no sirvieron de fuentes. Entre ellas destacaremos una del Vaticano ${ }^{25}$ por el colorido de su material, y otra del mismo lugar por sostener, como hizo acaso la nuestra, con la mano izquierda la embocadura del odre y con la derecha un rhyton ${ }^{26}$ : probablemente sea esta última estatua la que mejor refleja lo que debió de ser la escultura de Valdetorres.

\section{Desconocido A. (fig. 8)}

Fragmentos que lo componen: Conjunto formado por II-85, I-M-91, I-M-35, IV-798; y conj, for por II-84, I-M-21. $\mathrm{cm}$.

Altura probable de la figura completa: Unos 115

Estado de conservación: Reducida a la mano derecha y a un fragmento del pie derecho.

-Detalles técnicos: Se aprecian huellas de puntero en la parte inferior de la base, $\mathrm{y}$ de trépano entre el pie $\mathrm{y}$ la base. La parte delantera del pie se trabajó en un bloque aparte, y hay puntales entre los dedos de la mano.

2" B. Kapossy. Brunnenfiguren der hellenistischen und römischen Zeit. Zürich. 1969, apartado "Satyrn und Silene» (p. 30 y ss.).

"E. Espérandieu, Recueil général des bas-reliefs de la Gaule romaine, (reed en 1965), vol III, p. 366, $\mathrm{n}^{\circ} 2524$ y 2529

22 G. Lippold, Die Skulpturen des Vatikanischen Museums. Berlin, 1956, III, 2: Gall. Candel., IV, 95.

${ }^{21}$ E. Espérandieu, op.cit en nota 21, p. 408. Parecido es el de Nìmes: ibidem, p. 435.

24 A. Balil, Esculturas romanas de la Peninsula Ibérica. III (Studia Archaeologica, 60), Valladolid, 1980, p. 21, lám. XIII, $\mathrm{n}^{\circ} 54$. Este Sátiro presenta la cabeza reposando sobre un odre.

is G. Lippold, op.cit. en nota 22, p. 143, $n^{\circ} 56$. lám. 67.

26 Ibidem, p. 280, n" II, lám. 130.
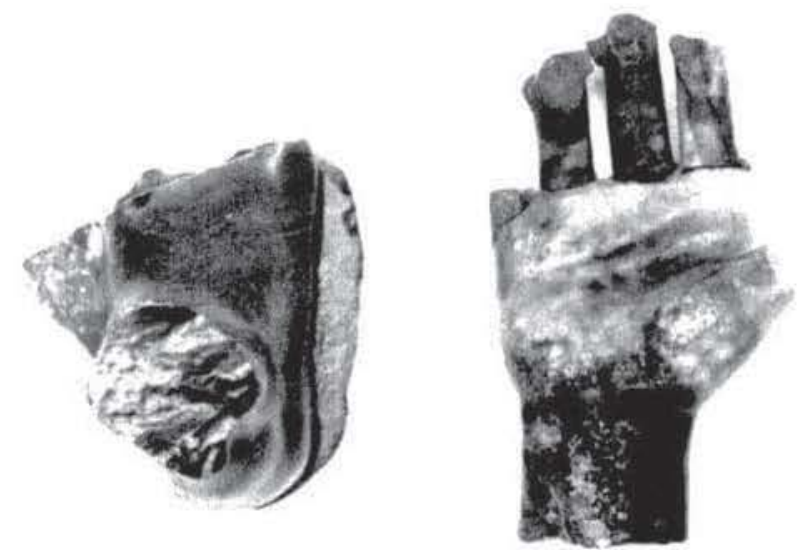

Figura 8-Desconocido A

- Notas descriptivas: Gran mano abierta y pie al parecer descalzo que, por su tamaño, pudieron pertenecer a la misma figura.

Basándonos en la forma de la mano y en la posición del pie descalzo, podemos deducir que esta estatua representa una divinidad masculina en pie. $\mathrm{Y}$ cabe resaltar que su tamaño hubo de ser marcadamente superior al de las demás estatuas de mármol gris oscuro veteado.

\section{Desconocido $B$ (fig. 9)} M-9.

Fragmentos que lo componen: V-470; 1-M-7: y I-

Altura probable de la figura completa: $U$ nos $90 \mathrm{~cm}$.

- Estado de conservación: Reducido a un fragmento de pierna izquierda con unos pliegues de tela, y a fragmentos de pierna y pie derecho.
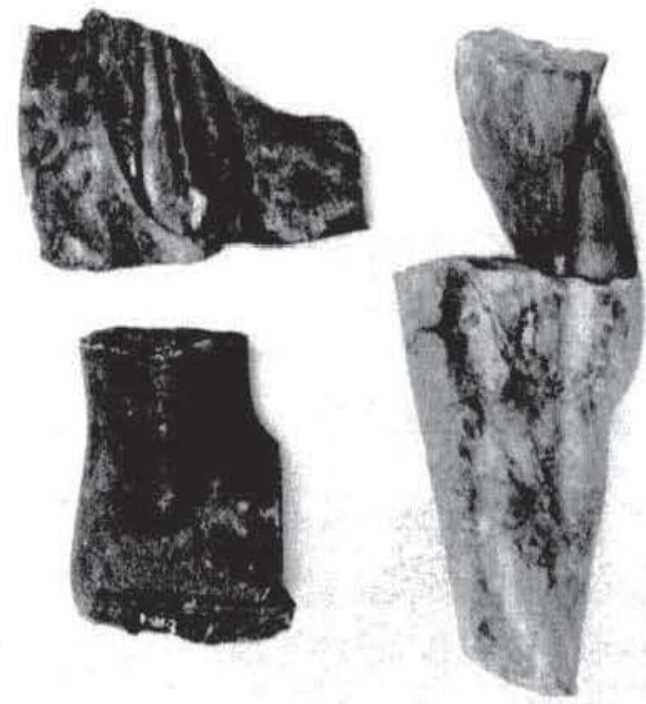

Figura 9.-Desconocido B. 
Detalles técnicos: La punta del pie fue tallada aparte. y la superficie de contacto correspondiente, alisada, presenta señales de puntero.

Notas descriptivas: Esta estatua se define sobre todo por el color de su mármol. con puntos grises sobre fondo negro.

Lo único que podemos decir de esta pieza fragmentaria es que representaba una figura masculina descalza, sin duda en pie, cubierta con lo que parece ser una clamide: hemos de pensar en la efigie de un héroe o de un dios juvenil.

\section{CONCLUSIONES SOBRE LAS FIGURAS EN MÁRMOL GRIS OSCURO VETEADO}

Como ya señalamos al comenzar este apartado, las siete estatuas que lo componen hubieron de constituir un conjunto muy homogéneo ${ }^{27}$. En consecuencia, lo más correcto es estudiarlas como tal, darles una unidad de cronología y de origen y, si es posible, buscarles un sentido como programa decorativo unitario.

Por lo que se refiere al primer punto, parece claro, a la luz de los distintos paralelos aducidos para cada estatua, que debe fijarse su talla entre el reinado de Adriano y los primeros años del siglo il d.C., lo que explica las restauraciones que necesitaron varias piezas antes de ser utilizadas en Valdetorres hacia el 400 d.C.

Más complicada nos parece la localización del taller: por una parte hemos hallado paralelismos en obras realizadas en Roma o su ambiente (sarcófagos de Gigantes y de Nióbides, estatuas de Sátiros) y hasta hemos aceptado que alguna pieza de carácter clasicista (el Gigante en concreto) se comprende mejor en este entorno. Sin embargo, el gusto ecléctico romano aceptaba la yuxtaposición de obras con matices ligeramente diversos; por tanto, haremos bien siguiendo el estilo dominante en el conjunto.

$\mathrm{Y}$ este estilo, al igual que la mayor parte de los paralelos aducidos, nos lleva más bien hacia los talleres de Asia Menor, y en concreto a la región de Afrodisias: alli se crearon y desarrollaron las gigantomaquias, allí nos remite la iconografia de los Ar-

\footnotetext{
27 Prescindimos aqui de la posibilidad, siempre resbaladiza, de aumentar el número de esculturas; pero cabe recordar que, como hemos señalado al hablar del Sátiro, pudo haber más de una fuente, y debe tenerse en cuenta que, además de los fragmentos asignados a cada obra, existen 10 fragmentos menores (incluido un tronco de apoyo y unos dedos) y unas 60 esquirlas sin adscripción clara: pudieron ser de cualquiera de las piezas estudiadas o a alguna otra desaparecida.
}

queros. alli se cultivó el estilo musculoso que domina en casi todas las figuras, e incluso allí es más factible hallar las canteras de mármol oscuro que sirvieron para tallar nuestras obras.

En cuanto al programa decorativo, acaso nos hallemos ante los restos escultóricos de una fuente dedicada a Apolo, quien sabe si en el ámbito de un santuario, de un teatro o de una via pública. Lo más claramente reconocible son los enfrentamientos del dios contra un Gigante y un Nióbide, es decir, dos pasajes que exaltan la fuerza de sus flechas divinas. Contemplamos, por tanto, un ciclo de gestas de Apolo, como el que adornó las puertas de su templo en el Palatino ${ }^{2 x}$ o como el que cubre los relieves, ya varias veces citados, del teatro de Hierápolis ${ }^{20}$ : este último conjunto coincide temáticamente con Valdetorres, pues, además de la epifania del dios y del episodio de Marsias, incluye el combate contra un Gigante y la muerte de los Nióbides " ${ }^{" .}$. ¿Quién sabe si el Desconocido A no era, en realidad, otro Apolo que, por su tamaño, dominaba el conjunto decorativo, y si el Sátiro, mediante algún aditamento (quizá una flauta doble), aludía al famoso competidor musical de nuestro dios?

\section{ESCULTURA EN MÁRMOL NEGRO}

La única estatua en mármol oscuro, de entre las halladas en Valdetorres, que no puede inscribirse en el apartado anterior, es la que representa a un nubio: para dar mayor realismo a su imagen, se esculpió en un material prácticamente negro y sin más vetas que alguna mancha gris oscura. Aunque, por su tonalidad y su grano fino, puede en algún caso extremo confundirse con algún fragmento de mármol gris antes estudiado, el análisis petrológico revela diferencias de cierta entidad ${ }^{31}$. Podriamos, por su semejanza con el material en el que están talladas otras figuras de negros antiguas, identificarlo como bigio morato oscuro ${ }^{32}$.

2x P. Zanker, Augusto y el poder de las imágenes, Madrid, 1992, p. 110. Alli se representaban la muerte de los Nióbides y la expulsión de los galos de Delfos (Propercio, II 31, 12-14).

${ }^{24}$ F. d'Andria y T. Ritti, op.cit, en nota 8, p. 12-13.

30 Esta última escena aparece en el ciclo de Artemis, pero cuenta con la presencia de Apolo (lám. 33 y ss.).

11 F. Mingarro Martín et alii, op.cit. en nota 2, p. 60, muestra $n^{\circ} 6$; ibidem, en p. 49, Cl, hay errata: en lugar de umuestra 7996 ( in sigla) (fig. 4)», debería decir «muestra 79996 (IV/591)».

32 El bigio morato era obtenido sobre todo en las canteras de Tenaro, en el sur del Peloponeso, pero también tiene minas en la zona occidental de Asia Menor y en las islas inmediatas del Egeo: E. Dolci y L. Nista, op.cit. en nota 4, foto 93 y p. 68; R. Gnoli, op.cit., p. $165-166$ y fig. $200 ;$ H. Mielsch, op.cit., lám. 16, n 544; M. L. Anderson y L. Nista (ed.), op.cit., p. 67.71 y fig 7. 
S. Vegrolfigs. 10 y 11 )

Frigmentos que to compenen. IV-1406. IV -136. con form por 111-897, IV-1313, II-87, IV-620, IV-617. conj, form por I-M-53, I-M-18. IV-584: IV-789: con! form por I-M-38, IV-517: conj form por IV-617. IV. $618, I V-62 x, 1-M-14 ; 1-M-32, I V-440, I V-393$, y IV-626

Altura probable de la figura completa: 1 nos $68 \mathrm{~cm}$. (porque esta arrodillada, en pie mediria unos $90 \mathrm{~cm}$.).

Estado de conservacion. Reducido a restos inconexos, solo se conservan dos fragmentos de la cabezat fel mayor, rajado y blanqueado por el fuego). ambos brazos casi completos (pero sin manos), la pierna y el pie derechos. el pie izquierdo y numerosos pliegues de ropaje.

Detallestecnicos: Esta estatua fue realizada tallando por separado distintas piezas y uniéndolas después mediante pernos. de los que se conserva uno (de hierro) y agujeros para alojar otros. Se trata, por lo demás, de una escultura relativamente mal acabada. pues se aprecian huellas sin retocar de cincel y de trépano. Hay leves marcas de puntero en las superficies destinadas a pegarse al pedestal. y en concreto en la punta del pie derecho. En la cabeza se aprecia una clara restauracion: el fragmento menor. en efecto, está realizado en mármol distinto, de color gris más claro. y muestra una talla relativamente tosea, con huellas de cincel desordenadas y agujeros de trépano sin retocar: contrasta, por tanto, con el fragmento mayor. donde se adivina, pese a la corrosión de la superficic, la talla de los rizos mejor ordenada y acabada. En este fragmento mayor se conserva un ojo, excavado para recibir en su interior otro material.

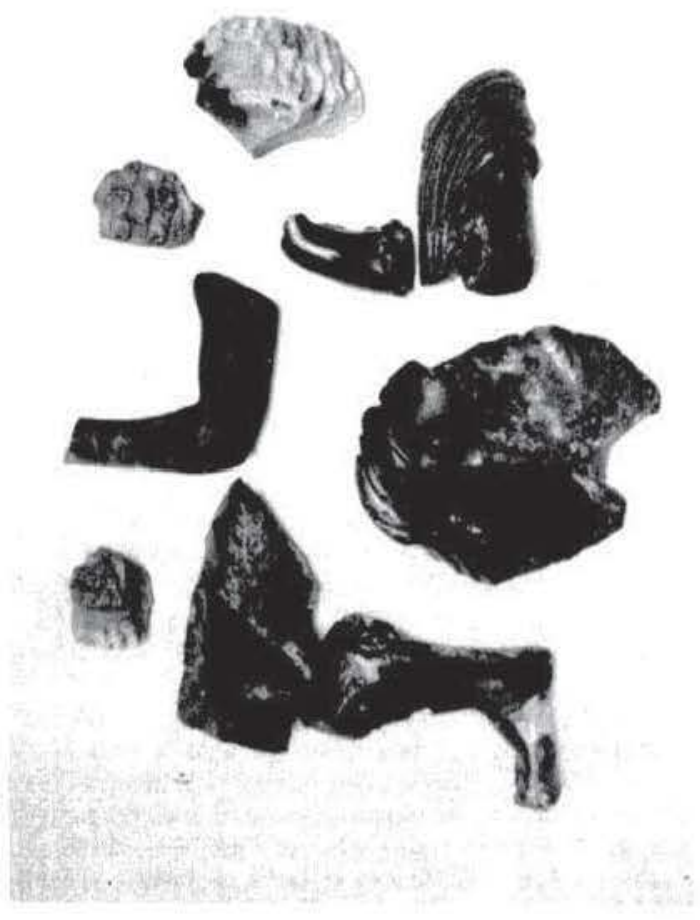

Figura 10.-Negro (cuerpo).
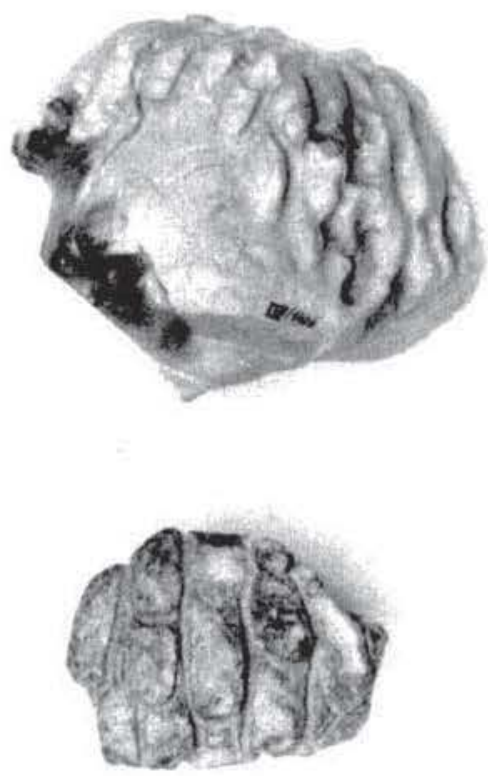

Figura 11. Negro(cabe/a)

Notas descriptivas: Con los fragmentos que conocemos, puede reconstruirse idealmente la figura de un negro arrodillado, con su peinado de rizos libicos, que doblaria sus brazos hacia adelante en actitud oferente, y que asienta la rodilla derecha en tierra. Está envuelto en una vestimenta de pliegues numerosos y peculiares: en efecto, vemos cómo la tela se ajusta girando en torno a la rodilla derecha, y cómo se dobla aparatosamente sobre el hombro izquierdo.

Esta figura se encuadra entre las múltiples imágenes de esclavos nubios que se realizaron en las épocas helenistica e imperial. Es norma que en estas obras se utilice un material oscuro (esteatita, mármol negro, bronce ${ }^{33}$ ) y se reserven los ojos en hueco para rellenarlos con otros materiales de colores $^{34}$; además, suelen ser figuras oferentes, unas veces en pie $y$ otras arrodilladas.

1 Recuérdense, por ej., el Negro de esteatita del Museo de Boston (M. B. Comstock y C. C. Vermeule, Sculpture in Stone. Boston, 1976, p. 71, $\mathrm{n}^{\circ}$ 112), o la cabeza de nubio del Museo de Brooklyn (C. C. Vermeule, Greek and Roman Sculpture in America, Berkeley, 1981, $\mathrm{n}^{\circ} 113$, lám. col. 12), o el bronce del Kestener Museum (Bildkataloge des Kestener-Museums. Hannover. Römische Bronzen, Hannover, 1964, n 63, lám. 24).

${ }^{34}$ Es el caso, por ej, de una estatua del Museo de Berlin, que muestra un nubio arrodillado, pero desnudo y con las manos atadas (Königliche Museen zu Berlin. Beschreibung der antiken Skulpturen, Berlin, 1891, p. 192, n 493). En el Museo de Estambul (G. Mendel, Catalogue des sculptures grecques, romaines et byzantines. Musées Impériaux Ottomans, II. Constantinople, 1914. p. 140) se reseña una cabeza de Negro, en mármol oscuro, que conserva en uno de sus ojos huecos el relleno de nácar. 
Sin embargo, y aun cumpliendo todos estos requisitos, el Negro de Valdetorres no tiene, al parecer, nungún paralelo exacto. Ciñéndonos a su tratamiento técnico, y en particular al de su cabello, cabe citar, por su parecido, una cabeza del Museo de las Termas, que se ha fechado en época adrianea ${ }^{35}$, otras (éstas en relieve) en un sarcófago de Baltimore, de fines del siglo 11 d.C. ${ }^{36}$, y un fragmento de Nueva York, ya del primer cuarto del siglo III d.C. ${ }^{37}$. Sus cronologias, por lo demás, pueden coincidir con la de nuestra pieza.

\section{ESCULTURAS EN MÁRMOL BLANCO DE GRANO FINO}

Cuatro son, en principio, las estatuas que se pueden reconstruir idealmente con este tipo de material, correspondiente a la «muestra $\mathrm{n}^{\circ} 2 »(\mathrm{p} .49, \mathrm{~A} /)$ del artículo de F. Mingarro et alii. Se trata de un mármol de grano fino y aspecto harinoso, al que se aplica la siguiente conclusión de dicho artículo: «algunos mármoles de los estudiados, especialmente los blancos, presentan caracteres muy próximos a los tipos italianos, especialmente a los de Carrara, pero también queremos hacer constar que algunos mármoles de Macael (Almería) tienen análogas características» (p. 70).

En este caso hemos de descartar, en principio, la unidad de origen de obras, tanto por lo común del material como por la clara diferencia de altura que se aprecia entre las distintas estatuas. Además, como veremos, por lo menos la Estatua Masculina Pequeña se diferencia de las otras por su trabajo muy refinado. En cambio, sí parece probable (y con tal hipótesis trabajaremos, aun sin quererla imponer como certeza) que, igual que Esculapio aparece con su serpiente, las Estatuas Masculinas Grande y Mediana, reducidas a fragmentos pero identificables como dioses, llevasen a su lado los dos otros animales de los que se han hallado restos: un grifo y una pantera. Y, puesto que el grifo parece mayor que la pantera, se lo atribuiremos a la Grande, dejando el felino para la Mediana.

${ }^{35}$ M. L. Anderson y L. Nista, op.cit. en nota 4, p. 68, fig. 7. Por desgracia, se discute la autenticidad de esta cabeza de bigio morato.

36 LIMC. s.v. «Aithiopes», 41.

37 Ibidem, 42. Puede añadirse también una cabeza de negrito de los Museos Vaticanos (W. Amelung, Die Skulpturen des Vatikanischen Museum, Berlin 1903, III,2: Gall. Candel., V, 32. lám. 168-169).

\section{Esculapio (figs. 12 y 13 )}

-Fragmentos que to componen: Conjunto formado por SALA-6 y SALA-7; IV-863; V-1371; y III-1071,

- Altura de la estatua conservada: $59 \mathrm{~cm}$. Altura probable de la figura completa: $72 \mathrm{~cm}$.

-Estado de conservación: A la estatua, una vez reconstruida, le faltan las siguientes partes: los pies desde la espinilla, y la posible base; los dedos medio y meñique de la mano derecha; la cabeza desde la base del cuello; el brazo izquierdo desde el codo; el bastón desde su arranque bajo la axila izquierda hasta cerca de la punta. y casi toda la parte media del cuerpo de la serpiente. Además, se aprecian corrosiones superficiales, localizadas principalmente sobre el pecho y sobre la parte superior de la espalda. El lado derecho de la cabeza de la serpiente está quemado.

-Detalles técnicos: Se aprecia trabajo de trépano en la parte inferior del manto, y huellas de cincel en la espalda y en la parte trasera del cuello. En el cuerpo y la cabeza de la serpiente, sólo aparecen bien tallados los detalles (escamas, etc.) en su parte más visible, que es la derecha en el caso de la cabeza.

- Notas descriptivas: La estatua muestra un hombre ligeramente inclinado hacia adelante $\mathrm{y}$ hacia su izquierda, que se apoya en un bastón mantenido bajo su axila izquierda; este bastón, según muestra un resto de puntal a la altura de la rodilla, corría junto a su costado, y en él se enrrollaba una serpiente con la cabeza hacia arriba. El personaje se envuelve en un manto sostenido sobre su antebrazo izquierdo, quedando a la vista parte del torso, y coloca la mano derecha sobre su cadera, mientras dobla el brazo izquierdo hacia adelante y hacia arriba. Por lo que se refiere a la calidad de la talla, es manifiesta la oposición entre el esquematismo de la parte trasera y el modelado carnoso, aunque un tanto banal y apresurado. de la musculatura y de los pliegues de la parte delantera.

La presente figura se inserta de lleno en el tipo conocido como «Asclepio Pitti», una de las imágenes mejor estudiadas de este dios. Dejando aparte representaciones parecidas en relieves, monedas y gemas $^{38}$, e incluso en ciertas esculturas un bulto redondo ${ }^{39}$, las réplicas "correctas" que se conocen de este modelo son las siguientes:

1. Estatua colosal de mármol griego, que se halla en Florencia, en el Palacio Pitti (LIMC, 382): es la copia más completa, que conserva la cabeza,

${ }^{38}$ Tomamos de nuevo como libro de referencia el $L I M C$, en este caso vol. II, s.v. «Asklepios» (por B. Holzmann). Véase aquí el $\mathrm{n}^{\circ} 382$.

${ }^{39}$ Incluimos aqui una gran estatua del Museo de Berlín (LIMC. 385), que B. Schlörb estudia en Untersuchungen zur Bildhauergeneration nach Phidias (Waldsassen, 1964), p. 31, lám. IV,1, como posible copia de un original del siglo v a.C.; y también cabria aquí una estatuilla de la Col. Hartwig (G. Becatti, "Opere d'arte grecea nella Roma di Tiberion, Arch. Cl. 25-26, 1973-1974, p. 20 , lám. XIV), cuyos pliegues parecen más cercanos a los del Asclepio tipo Velia (LIMC, p. 888). 


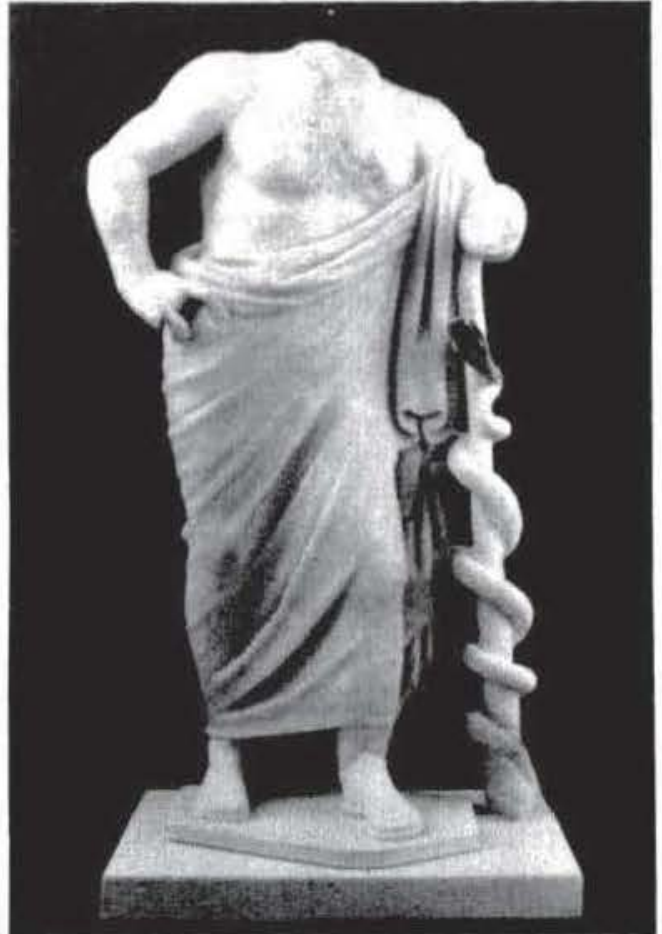

figura 12,- Esculapio restaurado, de frente.

la mano izquierda sosteniendo un volumen bajo la barba del dios. y todos los dedos de la mano derecha. G. Becatti. al estudiar el modelo que nos ocupa ${ }^{+1}$. fecha esta copia en el siglo $\| \mathrm{d} . \mathrm{C}$.

2. Estatua colosal conservada en Roma, en el Palacio Massimo alle Colonne (LIMC, 383): conserva el detalle de los pies calzados. Fechable en el siglo $\|$ d.C.

3. Estatua de mármol griego hallada en el Foro de Roma y conservada en su Antiquarium ( $L I M C$, 383 ): conserva la correcta colocación de la serpiente. Fechable quiza a principios del siglo III d.C.

4. Pequeña copia en paradero desconocido que se hallaba en el mercado anticuario de Roma y fue alli fotografiada. La publicó Becatti en su estudio (p. 20, lám. IX), fechándola en el siglo ॥ d.C.

5. Estatua inédita, conservada en la sala XXIII del Museo Arqueológico de Sevilla. Es sin duda la mejor réplica desde el punto de vista artístico ${ }^{41}$.

6. Aun siendo un relieve en marfil, no puede dejar de mencionarse el «Asclepio Pitti» representado en el Díptico Gaddi, del Museo de Liverpool ( $L I M C, 388)$, obra que se fechó en torno al 400 d.C.

7. Estatuilla en mármol recientemente hallada

\footnotetext{
${ }^{40}$ G. Becatti, op cit, en la nota anterior.

"1 Agradecemos desde aquí a Pilar León su interés por darnos a conocer esta magnifica obra.
}

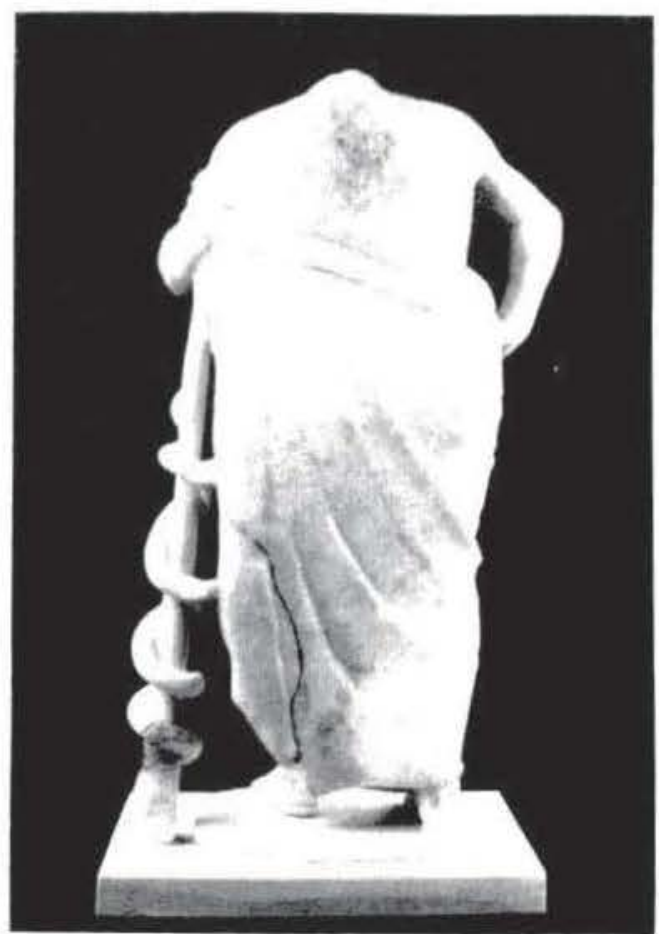

Figura 13. Esculapio restaurado, de espatalas

en Afrodisias ${ }^{42}$ : es una interpretación del tipo en estilo esquemático tardoimperial, y se fecha en el siglo $\mathrm{v}$ d.C.

De todas estas obras, la que más se parece a la Escultura de Valdetorres es, sin lugar a dudas. la fotografiada en el mercado anticuario de Roma. Tanta es su semejanza, en lo que permite ver la lámina publicada por Becatti, que podriamos incluso suponer un mismo taller de origen para ambas. Por desgracia, ignoramos dónde situar tal taller: acaso en la propia Roma, donde no faltaban modelos, o acaso en Grecia, cuyos mármoles locales sirvicron para realizar varias de las réplicas; al fin y al cabo, si nuestro mármol puede ser de Carrara o de Macael. no cabe olvidar que hay mármoles griegos que se confunden a menudo con el mármol hispano. En cuanto a la cronologia, creemos que debe darse un margen bastante amplio a una obra de trabajo tan mediano: puede ser antoniniana, pero también del siglo III d.C.

Sea como fuere, el Esculapio de Valdetorres aporta una novedad al tipo del «Asclepio Pitti»: es la única réplica que conserva entero el brazo derecho. $\mathrm{Y}$ no deja de ser un punto de interés, pues el modelo común, segủn G. Becatti y G. Heiderich ${ }^{43}$, era una fa-

42 K. T. Erim, "Recent Work at Aphrodisias 1986-1988", en Aphrodisias Papers (1), 1990, p. 29, fig. 30.

"G. Becatti y G. Heiderich, Asklepios, Diss. Freiburg im Bresgau, 1966 (citado en L.IMC, p. 895). 


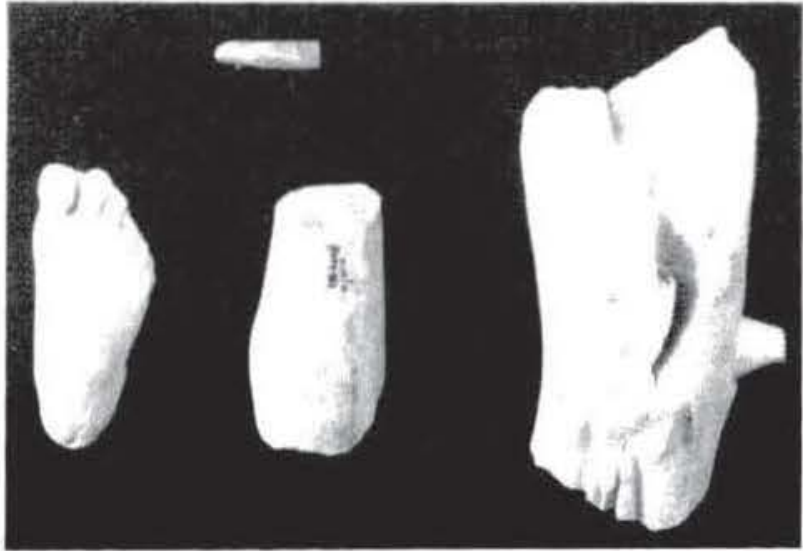

Tiguta 14. Lstatua masculina grande

mosa obra pergamenica realizada por Nicerato (siglo um a. ( .) y conservada en Roma. en el Templo de la Concordia.

\section{Estatua Masculina Grande (figs. 14 y 15 )}

Fragmentos que la cumponen: IV-601) III-2010: IV 603 a.b, c y d. I-M-58 a y b. y los fragmentos del grifo 1 . $\mathrm{M}-56$ : V-1115: 1-M-60: unido a 1-M-6.3 y a 1-M-6-4: I-M 65: I-M-62: I-M-42: IV-572: I-M-6) : I-M-66: IV-611. 1. M- 74 .

Altura probable de la tigura completa: I nos 100 $\mathrm{cm}$

Lstado de consersacion: lamo la figura humana como el grifo estan reducidos a minumos fragmentos: de aquélla quedan el pie derecto, un trozo de pierna izquierda. an dedo y fa parte alta de un tronco con pliegues de vestimenta: de éste, parte de la cabeza y plumas.

Detalles técnicos: In la figura humana. la base conserva golpes de puntero en la base inferior, y se observan huellas de cincel y de trepano en zonas poeo visibles. Bajo el troneo de apoyo hay un agujero de perno. para fijar la escultura al pedestal. Fn el grifo se ven huellas de trépano y cincel. puntales entre pluma y pluma. y un agujero de perno en una pluma, para fijarla o restaurarla.

Detalles descriptivos: La presencia del tronco y del pie sobre su fina base sugiere una figura en pic, y la vestimenta que cae vertical sobre el tronco parece una clámide. Por su parte, el grifo muestra el virtuosismo técnico de tallar las plumas por separado, aunque ello dificultase el pulimento de algunas zonas.

Aun reducida a restos minimos, esta estatua descalza ha de representar a un dios erguido vestido con una clámide. Tal detalle cuadra, una vez más. con la iconografia convencional de Apolo, lo que refuerza la hipótesis de la presencia del grifo a su lado. Por lo demás, muy poco podemos decir, sino

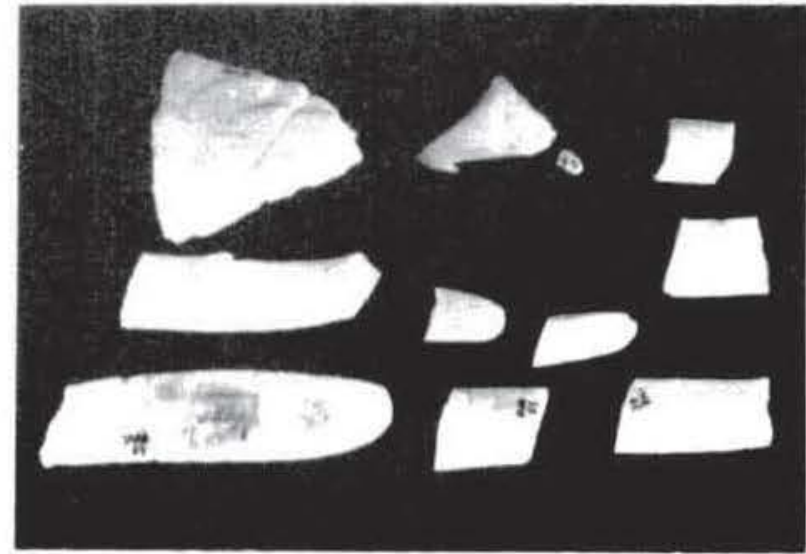

ligura 15. Ciritio

que el pic, con su forma aplanada muy clasicista. nos invita a pensar en una copia de original griego. $\mathrm{y}$ en una cronologia en torne al siglo $11 \mathrm{~d} \cdot \mathrm{C}^{+4}$.

\section{Eisatua Masculina Mcdiana (figs. 16 y 17 )}

Fragmentos que la componen: Conjunto formado por IV-424, IV-605: com form por IV-606 a y b. IV6017: III-881: dos tragmentos de baston que pueden coresponder tambien a la I statua M Pequena 1 -M-59. y 77-72.17: y factabea de pantera: III-882

Altura probable de la figura completa: 4 hos $80 \mathrm{~cm}$

I stade de conservacion: Quedan partes de las dos piernas, el pie derecho, la parte inferior de un tronco de

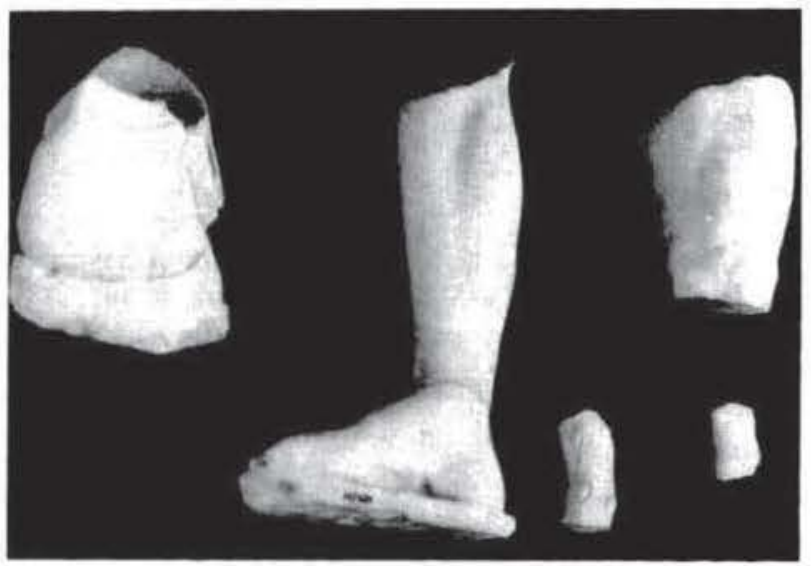

Figura 16. I:statua masculma mediana

it A estas mismas fechas nos remite el tipo de tronco vease F. Muthmann, Stathenstiitzen. Heidelbery, 1951. p. 37 y ss. lam. $\checkmark$ y s

* Dada la semejanza de marmol y lo fragmentario de las pezas, hay, ademas de los fragmentos citados, hasta 16 fragmentos menores y 27 esquirlas que pueden atribuirse indistintamente a cualquiera de las estatuas de este apartado. 


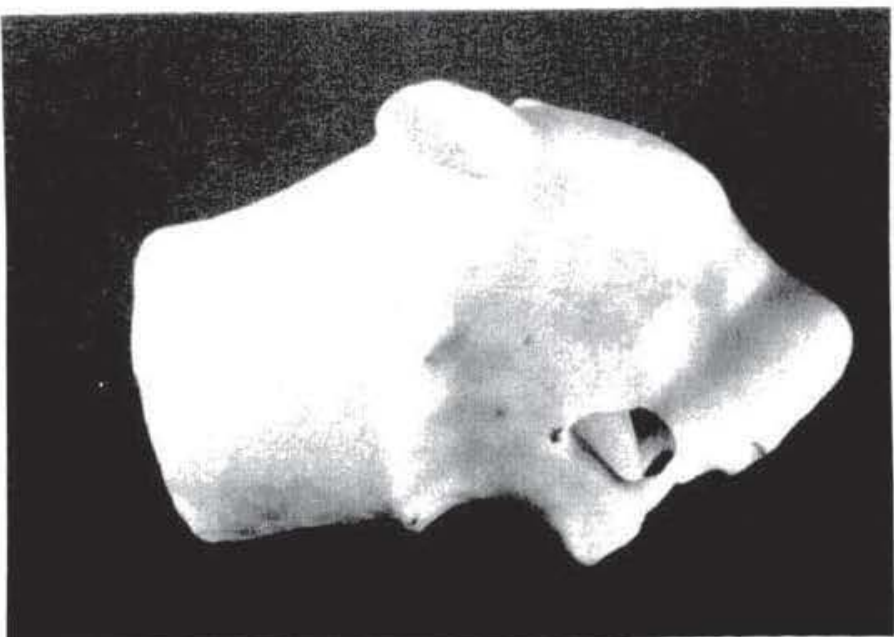

Figura 17. Cabceat de panterat

apoyo, Y. acaso, festos de un tallo o baston con nudos, de la pantera. solo la caticza.

Detalles tecnicos: Ademas de etertas huellas de ferramentas en la superticic. se ve un agujero de permo para tifar el tronco al pedestal. La cabesa de la pantera mucxira su lado i/quicrdo metamente esbosado

Detalles descruptivos: La figura estaba en pie y portaba acaso un bastón con nudos: si la pantera realmente formaba grupo con el. hubo de estar al lado de su piema derecha, murando hactat arriba y con la parte isquerda de su cabeza muy proxima a dicha pierna.

Como en la obra anterior, nuestras observaciones han de ser pocas y cautelosas: sin duda nos hallamos ante un dios descalzo en pie, y, dados sus probables atributos, podemos pensar en un Baco o un joven satiro to. En cuanto a la iconografia, la situaremos entre los siglos $\|$ y $I 11$ d.C., sin poder precisar más.

\section{Estanua Masculina Péueña (fig. 18)}

Fragmentos que la componen: Conjunto formado por III-23I, IV-536: IV -518: conj, form, por IV -565 , IV571: 111-15: y acaso los dos fragmentos de bastón nudoso mencionados en la pieza anterior. $75 \mathrm{~cm}$.

Altura probable de la figura completa (erguida)

Fstado de conservación: Reducida a restos de la rodilla i/quierda y a fragmentos de un brazo y de telas. además del posible baston.

Detalles técnicos: Muy escasas huellas de cincel y de trepano en lugares poco visibles.

Detalles descriptivos: Frente a las piezas blancas anteriores, la presente se caracteriza por un trabajo mu-

in I:xiste, en efecto, fa iconografia de un Satiro o Fauno con baston y pantera: S Remach, Ripertoire de la statuaire grecque ef romaine I, Paris, $1930\left(3^{3}\right.$ ed.), p. 307. sho mas retinado y perfecto fiste se esompractoa sobre

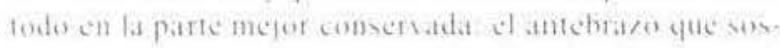
thene los pliegues de untetamide lse detalle de resti. mentat. junte a la fuer/a de la rodillat. Hos permite dents-

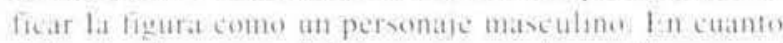
al bastont. fo mas probable es que sea de esta tigura. por sti tina talla.

En el caso de estat estatua. Ignoramos si estaba o no de pre: lo tunce que sabemos es que levantaba un bra/o. y con el los plicgues de una clamide ondeando al viento, Podriamos pensar, por tanto. en un dios o un heroe. y. si aceptamos como atributo suyo el baston. nuestras sugerencias se encaminarian hacia algun heroe de vida campestre. como Acteon. Indimón, etc. Por lo que se reficre a la cronologia. no podemos ser precisos; sus abarrocados pliegues son. en efecto, muy comunes en sarcotiagos romanos de epoca antoniniana y de la primera mitad del siglo m d. C. ${ }^{4}$. pero aun se mantienen en ciertas obras del Bajo lmperio" ${ }^{2}$ solo el sistema de proporciones de la figura nos permitiria decantarnos por una u otra fecha.

\section{LSCULTURA EN MARMOL BLANCO DE GRANOGRUESO}

Reunimos aqui en un conjunto hipotético todos los fragmentos hallados en este material, que el articulo de F. Mingarro et alii estudia en p. 53, D/y

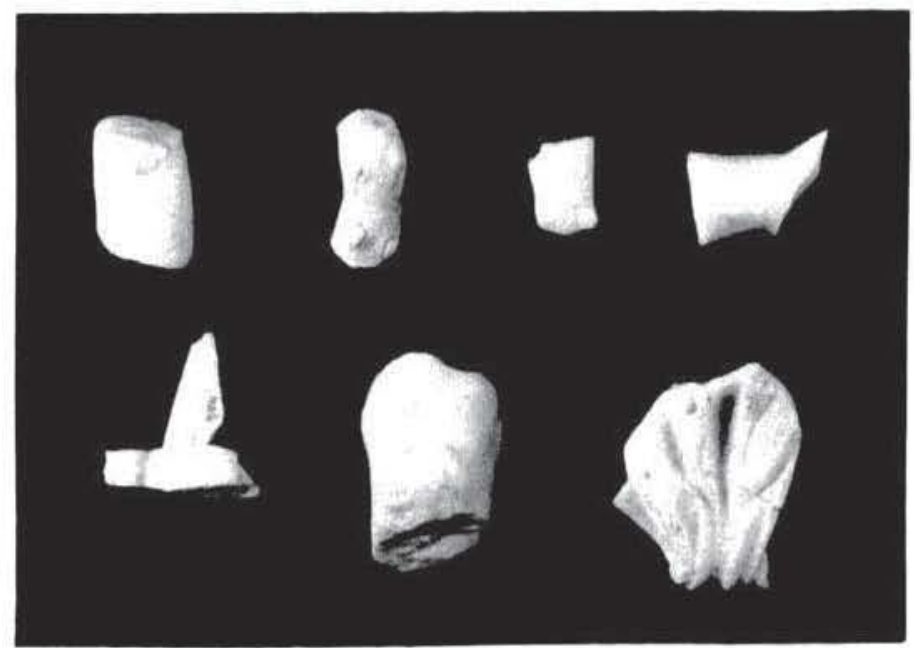

Figura 18. Estatua masculina pequeña

it Veanse, por ej.. un sarcófago de nobides de h. $150 \mathrm{dC}$ (II. Sichtermann y G Koch, Griechische Mvthen auf römschen Sarkophagen. Tubingen, 1975. Kat. 47), o dos sarcofagos con el tema de Aquiles fechables en el siglo ilt d. C. ILIMC: s. . "Achilleus", 139 y 699).

is Vease, por ej. la Diana de Saint-Cieurges-de-Montagne (LIMC: s.1: «Artemis Diana”, 376). 
como «muestra n" l». A titulo indicatıro, scenalaremos su semejanza con mármoles blancos de las islas del Fgeo.

\section{Estatua con agruila (fig. 19)}

Fragmentes que la componen: Conjunto formado por IV-6011. IV-608, 1-M-29. IV-56- V-224, 1-M-8. IM-31: I-M-30: 11-240: V-225: y diversas esquirlas.

Altura probable de la ligura (erguida): $80 \mathrm{~cm}$

1-stado de conservacion: Solo se conservan restos de la pierna y el pie i/quierdo y de un brazo y un antebrazo, ademais de la cabera de un aguila sestemendo unos pliegues.

Detalles tecnicos: Hay huellas de cincel y de trepano en los pliegues.

Detalles descriptivos: Aunque los restos de figura humana y la eabeza del iguila sostenendo unos panos no tienen otro nexo de unión que la calidad del material. y por tanto puedieron formar parte de distintas estatuas. la propia rareza del marmol nos invita a pensar en una picza unitaria. Sill cmbargo. to unico que podemos ar chturar es la colocación del aguila a un lado de la figura humana. levantando con el pico un extremo de su vestimenti.

Solo caben sugerencias ante esta estatua insegura. La persona representada parece muy poco musculosa (acaso una mujer o un niño) y ello invitaria a pensar en alguno de los amores de Júpiter desvelado por el ave de su señor. Sin embargo, desconocemos paralelos concretos para nuestra posible imagen, y una de las iconografias más desarrolladas en este contexto, la de Ganimedes, no muestra el águila soteniendo telas en ninguna de sus manifestaciones conocidas ${ }^{40}$. Por lo demás, la obra puede fecharse en los siglos 11 o $11 \mathrm{~d}$ d. $\mathrm{C}$.

\section{FRAGMENTO ESCULTÓRICO EN MARMOL ROJO}

Basta una nota para dejar constancia del pequeño fragmento IV -599 , realizado con casi total seguridad en mármol rosso antico ${ }^{50}$. Su talla representa un pliegue de tela ondulado con la parte posterior lisa, y resulta atractivo pensar que sirviese de apli-

\footnotetext{
49 Consúltese el libro fundamental de II Sichterman, Gian med. s.a., o LIMC: IV. s.v. "Cianymedes", por el mismo autor.

Fste mármol se halla en las canteras de Tenaro, en Girecia. y existen variantes en la cona de Afrodisias. Véanse: L. Laßari. ni, "Rosso antico and other Red Marbles...n, en Martle. Malibu. 1990, p. 237-251: E. Dolci y L. Nista, op cit en nota 4. fotos 106-108, p. 71-72; R. Ginoli, op.cit. p. 160-164; H. Mielsch. op.cit. lám. 17, n 596 y 599: M. L. Anderson y L. Nista (ed.). op.cit. p. 95-101.
}

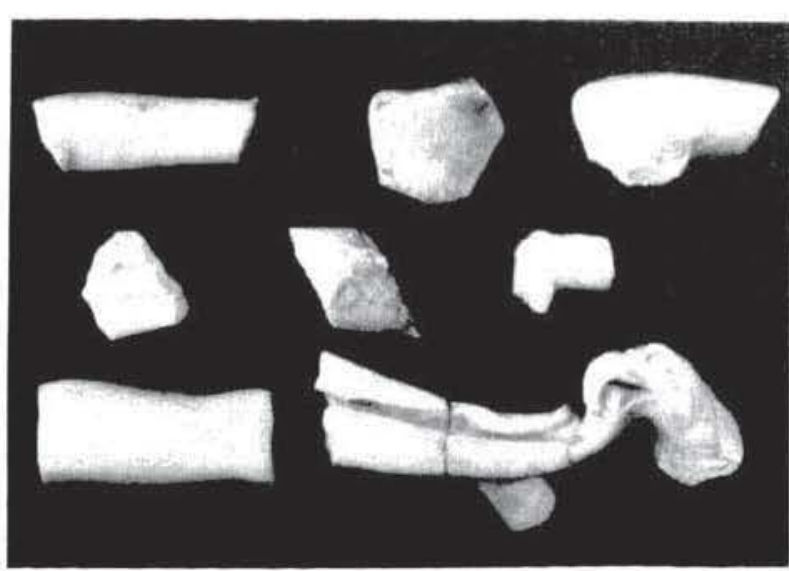

Tiguri 19- Estatua con iguila

que colorista para una de las estatuas del apartado I: pudo, por ejemplo, formar parte de la clamide del Niobide.

\section{PFDESTALES EN MARMOL. BLANCO (figs. 20 y 21 )}

Todos los pedestales para estatuas hallados en Valdetorres estan realizados con el mismo material un marmol blanco de grano grueso, de textura rugosa y aspecto muy brillante ${ }^{-1}$, fácil de distinguir (sal vo en pequeñas esquirlas) del visto en la Estatua con aguila.

Los fragmentos identificados son siete: $77-72-2$ muestra un pedestal en forma de herradura: 77-72-3 y $1-\mathrm{M}-26 \mathrm{co}-$ responden a pedestales rectangulares: y $\mathrm{V}-1175$ (una esquina), I-M-39. IV-583 y IV-805 (restos varios) no permiten concretar una forma. La altura oscila entre 6 y $8.5 \mathrm{~cm} ., \mathrm{y}$. mientras que el primero tiene un diametro de $32 \mathrm{~cm}$. uno de los dos pedestales rectangulares superab: los $35 \mathrm{~cm}$. de longitud.

Los perfiles más a la vista están tallados con moldura de escocia entre dos listeles, aunque con pequeñas variantes; en cambio, son lisos los perfiles de las partes traseras. La parte inferior de los bloques suele aparecer toscamente desbastada a puntero: sólo se cuida y pule su borde. La parte superior muestra un rehundimiento (para recibir la base de las estatuas) trabajado a puntero y con un agujero para perno.

Este tipo de pedestales, por su propia sencillez. es dificil de fechar: sin embargo, sus paralelos más

\footnotetext{
4. Lingarro et alii. op.cil. p. 54, E/, y "muestra n" 3n.
} 


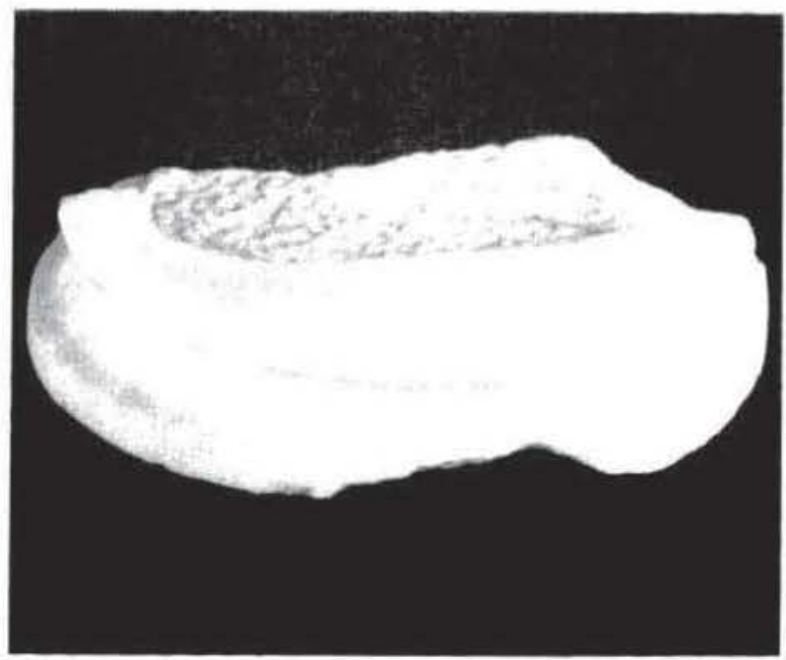

Higura 20. Pedestal

directos por la forma y talla de la moldura se hallan tanto en el conjunto de Silahtaraga como en crertas obras durante el Bajo Imperio ?

Por lo que a Valdetorres se refiere, la uniformidad en marmol y talla de los pedestales. en contraste con lo heterogeneo de las estatuas, parece sugerir que aquéllos no fueron realizados junto a éstas. sino que fucron tallados, acaso con marmol y mano de obra locales, para acondicionar las obras de cara a su colocación en la villa.

Resulta imposible, desde luego, emparejar los pedestales con las estatuas conocidas. Sólo la lógica nos permite suponer que los pedestales en forma de herradura se utilizasen para figuras aisladas estáticas, y que los grupos y las figuras en movimiento hubiesen de ir sobre largos pedestales rectangulares. Por lo demás, la talla de los pedestales demuestra que fueron pensados para estatuas visibles sólo de frente, y quizá desde un punto de vista bajo, porque suelen alcanzar más altura por la parte de atrás.

\section{CONCLUSIONES}

Si, a la luz de cuanto hemos visto en las páginas anteriores, hubiésemos de definir con una sola palabra el conjunto escultórico que nos ocupa, ésta no

7. Vease la ya citada Artemis de Saint-Georges-de-Montagne. junto a la Afrodita que aparéó con ella (E. Espérandieu, op.eit en nota 21, vol. 11. p. 221, o el famoso "Cristo como Macstron del Museo de las Termas (A. Giuliano et alii, Museo Nazionale Romano Le sculture, 1.1, Roma, 1979, p. 192): u otras esculturas en L. Bonfante y C. Carter, "An Absent Herakles and a Hesperid: a Late Antique Marble Group in New Yorkn. A.IA, 91. 1987. p. 247 y 55 , fig. $1-3,7-9$ y 11 .

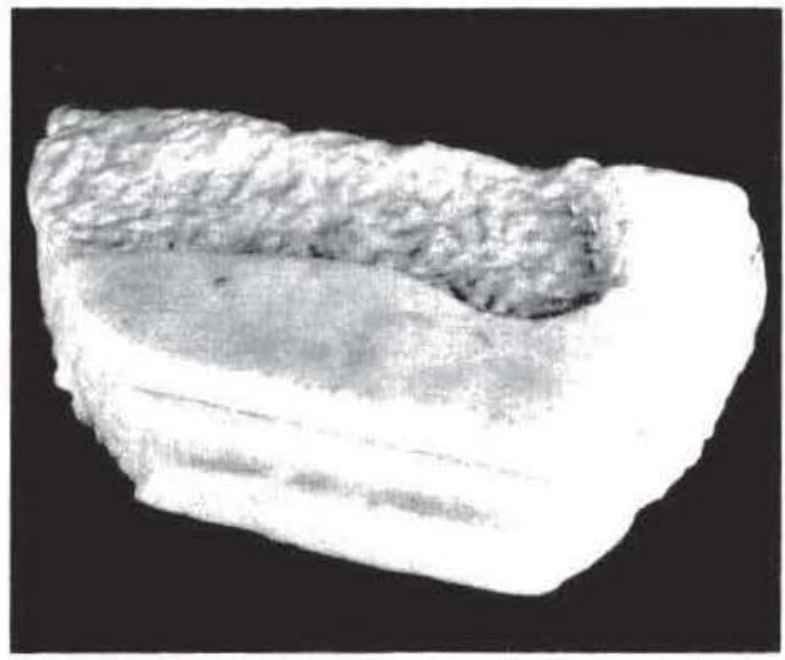

Iigura 21 Pedestal.

podria ser otra que "coleccions, con cuanto supone este termino dentro de la sociologia del arte. El hombre que decoró el edificio de Valdetorres tenia entre sus manos diversas obras de variados origenes, desde las estatuas de un monumento dedicado a Apolo hasta la figura doméstica de un nubio, pasando por unas imágenes de dioses, y decidió exponerlos, ya decontextualizados, en el peristilo o en las salas que se encontraban a su disposicion. Ni siquiera le preocupo carecer de agua corriente a la hora de colocar esa fuente decorativa que era el Satiro con odre.

Las obras con las que contaba eran ya antiguas. pues podian fecharse entre los siglos 11 y III d.C : doscientos años habian pasado desde que fueran esculpidas, y en ese tiempo habian sufrido desperfectos y consiguientes restauraciones ${ }^{53}$. Por tanto, eran ya verdaderas "antigüedades» susceptibles de sumar a su sentido iconográfico y artístico, propio del momento de la creación, un sentido distinto y nuevo: el de su prestigio cultural. Dos facetas de gran interés, que han de ocupar, una tras otra, nuestros últimos párrafos.

"Estas reparaciones, junto con el detalle de la fuente sin agua que acabamos de citar, son otros tantos datos definitivos en favor de la reutilización, $y$ por tanto de la antigüedad de las esculturas. Con ello queremos taxativamente apartar nuestras obras de la polémica creada ultimamente por las inscripciones de unas esculturas de Copenhague, que podrian sugerir la continuidad del estilo helenistico en ciertos talleres de Afrodisias hasta mediados del siglo iv d.C. Sobre esta discusion. véanse, por cj.. K Erim y C. M. Roueche, "Sculptors from Aphrodisias. Some New Inscriptions", BSR, 50, 1982, p. 102-115; M. Moltesen, "The Aphrodisian Sculptures in the Ny Carlsberg Glyptotekn, en Aphrodisian Papers (1). 1990, p. 133-146: M. Floriani Squarcrapino, "La scuola di Aphrodisias (dopo 40 anni)", ibidem. II. 1991. p. 123-126: N. Hannestad, Tradition in Late Antique Sculpture. Aarhus, 1994 


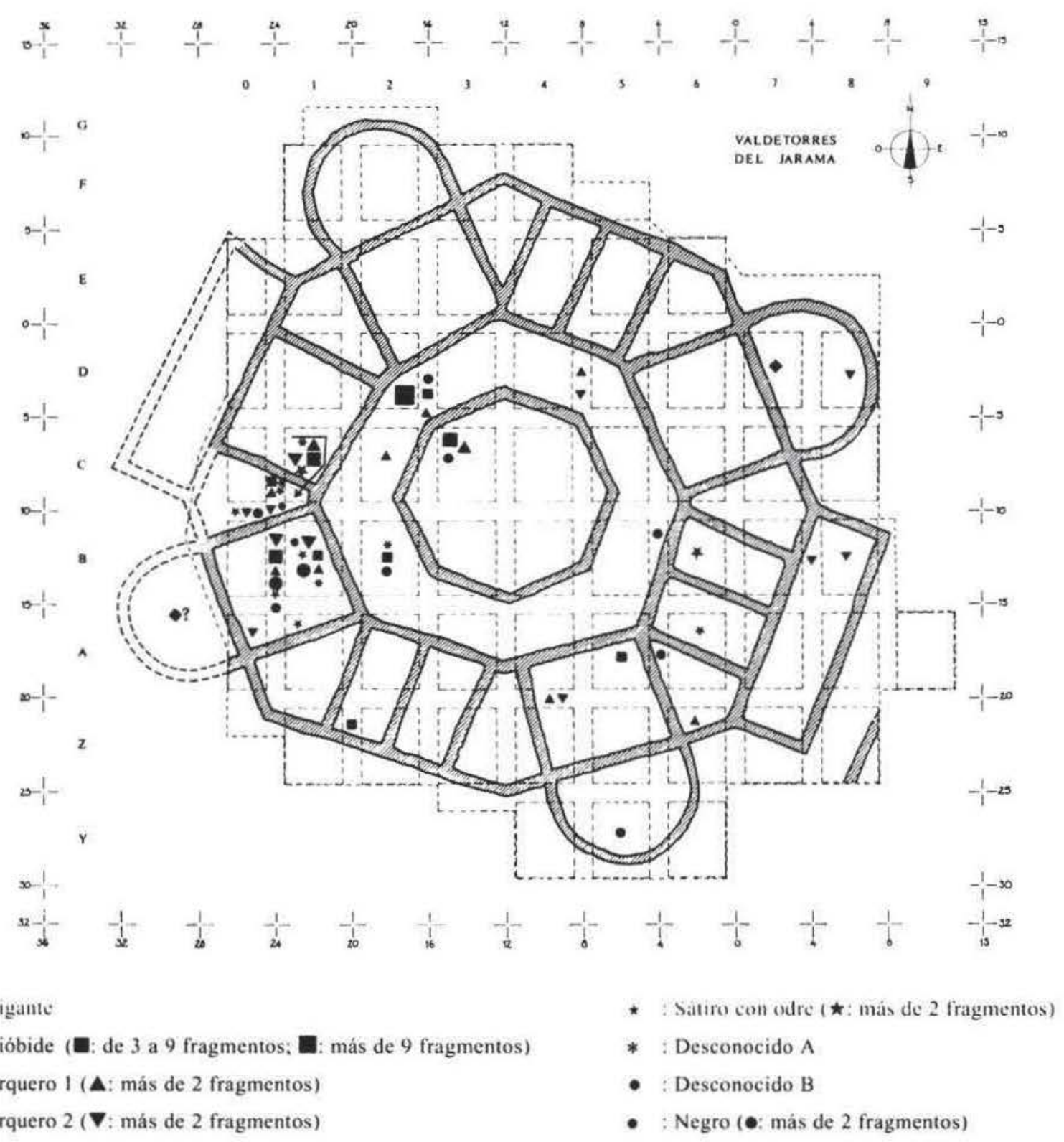

Figura 22.-Plano con la situación de los hallazgos de mármol negro. 


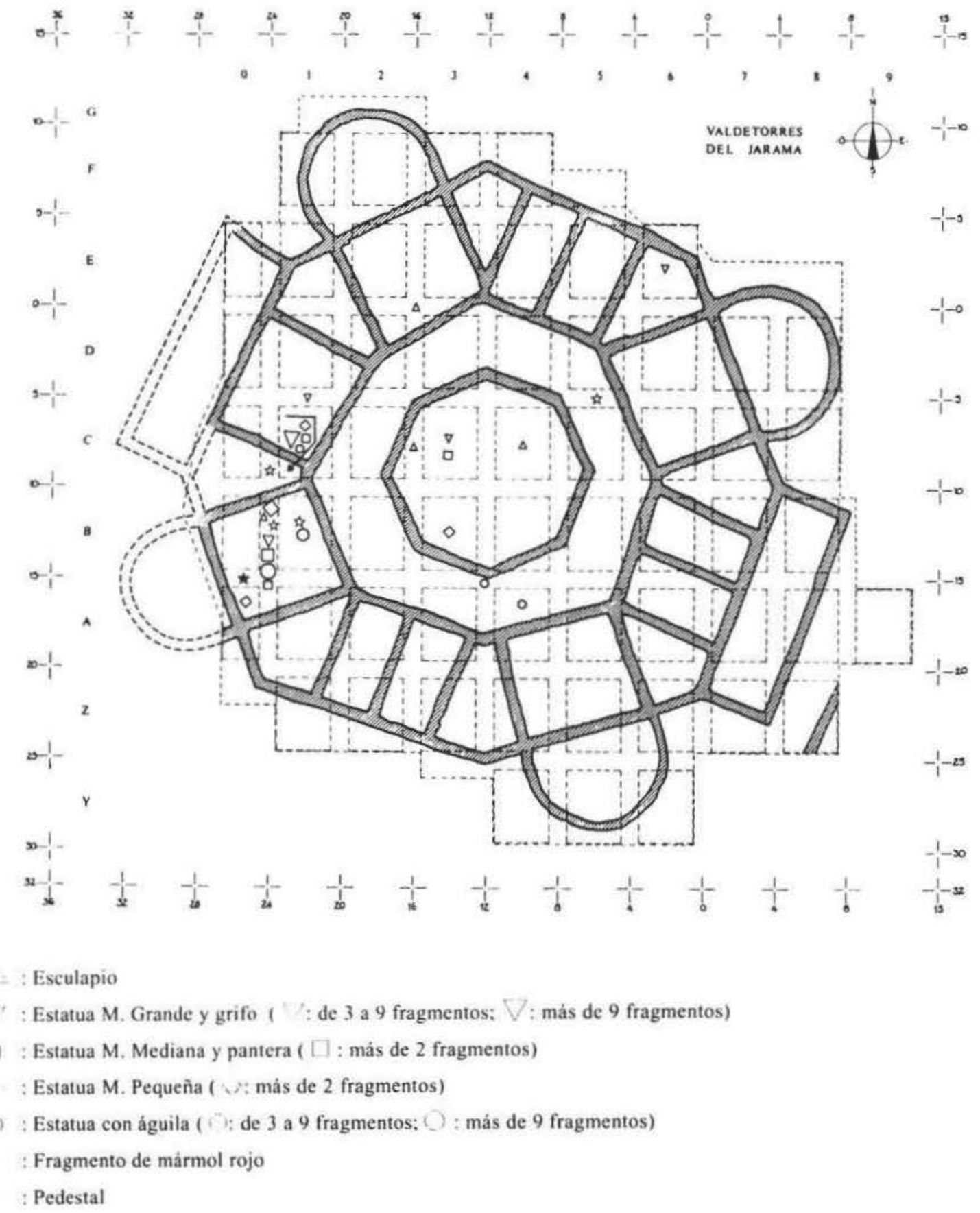

Figura 23.-Plano con la situación de los hallazgos de mármoles blanco y rojo. 
Poco diremos, sin embargo, de la primera, porque es la que ha centrado el estudio particular de cada una de las piezas, $y$, al ser muchas de éstas independientes, carece de sentido plantearse una sintesis imposible. Tan sólo recordaremos, como dato de máximo interés, la aportación del Esculapio a la iconografia del "Asclepio Pitti», la novedad del Negro entre las imágenes de su iconografia, el contexto desconocido del águila sosteniendo una tela en el pico y, sobre todo, el intrincado nudo de problemas que plantean las figuras en mármol gris veteado.

Sin ánimo de volver atrás, si merece la pena resaltar el valor artistico de este último conjunto, acaso salido de los talleres de Afrodisias o su ambiente. Los grupos de Apolo y el Gigante y de Apolo y el Nióbide tienen muchas posibilidades de poder ser considerados obras originales, no copias, y constituyen por tanto jalones de interés en la larga trayectoria de grupos escultóricos bidimensionales, tan apreciados en la escultura helenística y romana ${ }^{54}$. Su calidad, en efecto, es muy digna, y la existencia de prototipos parecidos para cada figura aislada no excluye la creatividad de un taller con inspiración.

Mas, si el valor artístico de las esculturas de Valdetorres es grande, no es menor, desde luego, el significado de su reutilización en torno al 400 d.C.: nos hallamos ante una de las mayores colecciones de estatuaria clásica reunidas por un particular durante el Bajo Imperio ${ }^{55}$, y, desde luego, ante la mayor encontrada hasta ahora en Hispania, pese a que en nuestra peninsula es bastante común la presencia de esculturas altoimperiales en las villas de los siglos iv y $\vee$ d.C., como ha demostrado E. M. Koppel ${ }^{\text {s. }}$.

\footnotetext{
Recuérdense, en esta trayectoria, obras como un grupo de niños luchando que estuvo en Vienne (A. Herrmann, "The Biter: a Late Hellenistic Astragal Player", en A Tribute to P. II. von Blanckenhagen. New York. 1979, lảm. XI.VIII,2), o el Baco sobre un asno conservado en Minneapolis (C.C. Vermeule, op.cit. en nota 33, p. 206, $\mathrm{n}^{\circ}$ 171), o el Aquiles y Troilo de Santa Bárbara (M. A. del Chiaro, Santa Burhara Musemm of Art. Classical Art. Sculpture, Santa Bárbara, 1987, p. 76-79, n 30; o grupos tan conocidos como el Laocoonte, las Tres Gracias o los Ciervos de la Casa de los Ciervos de Herculano, etc., hasta llegar al Bajo Imperio, con obras como la Venus de Narbona, hoy en el Louvre (D. M. Brinkerhoff, A Collection of Sculpture in Classical and Early Christian Antioch. New York, 1970, fig. 47), o la Venus de Side (J. Inan, Roman Sculpture in Side, Ankara, 1975, p. 41. $\mathrm{n}^{\circ} 8$, lám. XX).

5s Véase sobre todo D. M. Brinkerhoff, op.cit. passim, y, sobre todo, p. 54 y ss.

st E. M. Koppel, «Die Skulpturenausstattung römischer Villen auf der lberischen Halbinsel», en W. Trillmich ct alii (ed.). Hispania Antiqua.Denkmäler der Römerzeit, Mainz am Rhein. 1993, p. 193-203. Véase también D. Vaquerizo Gil, "La decoración escultórica de la villa de El Ruedo (Almedinilla, Córdoba), AnACórdoba. 1, 1990, p. 125-154.
}

A partir de estos datos, resultaría de sumo interés plantearse problemas más amplios, que exceden desde luego los objetivos de estas páginas: hasta qué punto, por ejemplo, influyeron las leyes antipaganas de Teodosio en el paso a manos privadas do muchas esculturas mitológicas situadas en lugares públicos: o cómo se combinó su uso decorativo en villas con mosaicos. plateria o marfiles de temas paganos: qué papel tenian en este coleccionismo el prestigio cultural de la Antigüedad (lásica y la religiosidad de cada propietario: o. en otras palabras. hasta qué punto estas efigies de dioses fueron reunidas por afán estético, o por deseo de salvarlas de las iras cristianas.

Sin llegar tan lejos, si que podemos aproximarnos al caso concreto de Valdetorres, donde sabemos que hubo marfiles tallados con imágenes mitológicas (una Ninfa, por lo menos), y que, pese a su riqueza, fueron destruidos como las estatuas ${ }^{57}$; parece difícil no creer en un móvil religioso de los saqueadores, que acaso respondia a una actitud semejante del coleccionista.

Finalmente, parece de rigor, antes de concluir, volver a la comparación con un conjunto que, a primera vista, parece muy semejante al de Valdetorres: nos referimos al de Silahtaraga, que ya mencionamos al hablar del Gigante ${ }^{5 x}$. Consta de una serie de deidades en mármol blanco, unas de grano grueso y otras de grano fino, muy fragmentadas, pero que hubieron de ser de distintos tamaños. Además, hay hasta seis Gigantes esculpidos en mármol gris negruzco semejante al nuestro e instalados sobre pedestales de mármol blanco. Estas figuras oscuras muestran, como el caballo del Nióbide, los globos oculares vacios, preparados para recibir otra materia. Además, es normal el uso de pernos para juntar piezas elaboradas aparte ${ }^{54}$.

La semejanza, sin embargo, se reduce bastante si se tienen en cuenta otros factores: en Silahtaraga, al parecer, se puede hablar de una verdadera gigantomaquia como tema iconográfico, y el conjunto se colocó en una capilla junto a una via en época severiana, es decir, poco después de tallarse las obras. En consecuencia, el paralelismo queda limitado a algún tema concreto (iconografia del Gigante) y a semejanzas de estilo y de ejecución con nuestras

\footnotetext{
\&Véase M. Carrasco y M. A. Flvira, op.cit. en nota I. passim.

${ }^{5 \times} \mathrm{N}$. de Chaisemartin y E. Orgen, op.cit en nota 7, passim.

54 Sobre las esculturas realizadas por partes y después ensambladas, véase A. Claridge, "Ancient Techniques of Making Joins in Marble Statuary", en Murble. Malibu, 1990. p. $135-162$.
} 
figuras de mármol gris veteado, es decir, a nuevos argumentos en favor del origen microasiático de estas últimas piezas. En cuanto al detalle de los pedestales blancos añadidos, ignoramos si en el caso de las piezas grises de Silahtaraga puede hablarse de restauraciones; pero nos reafirmamos en la probabilidad de que lo fuesen en las esculturas de Val- detorres: de otro modo no se explicaria, por ejemplo, que en nuestro conjunto aparezcan árboles de apoyo para las esculturas blancas y grises, que carecen de sentido cuando la base no forma bloque con la estatua. Además, cabe recordar que las estatuas blancas de Silahtaraga tienen pedestales normales, y no anadidos como ocurre en Valdetorres. 